\title{
Trpm8 modulates thermogenesis in a sex-dependent manner without influencing cold- induced bone loss
}

Adriana Lelis Carvalho, $\mathrm{PhD}^{1}$, Annika Treyball, BA ${ }^{1}$, Daniel J. Brooks, MS ${ }^{2}$, Samantha Costa, $\mathrm{BS}^{1}$, Ryan J. Neilson, BS ${ }^{1}$, Michaela R. Reagan, $\mathrm{PhD}^{1,3}$, Mary L. Bouxsein, $\mathrm{PhD}^{2}$, Katherine J. Motyl, $\mathrm{PhD}^{1,3} *$

${ }^{1}$ Center for Molecular Medicine, Maine Medical Center Research Institute, Scarborough, ME ${ }^{2}$ Center for Advanced Orthopaedic Studies, Beth Israel Deaconess Medical Center, Boston, MA ${ }^{3}$ Tufts University School of Medicine, Tufts University, Boston, MA

Grant Funding:

K01AR067858 to Katherine Motyl, PhD, Principal Investigator

P30GM106391 to Robert Friesel, PhD, Program Director P30GM103392 to Don St. Germain, MD, Program Director P20GM121301 to Lucy Liaw, PhD, Program Director U54GM115516 to Clifford Rosen, MD, Program Director

*Address correspondence to:

Katherine J. Motyl

81 Research Drive

Scarborough, ME 04074

(207) 396-8004

motylk@mmc.org

Figures: 7

Tables: 3

Supplementary Figures: 1

Supplementary Tables: 1 


\section{Abstract}

$48 \operatorname{Trpm} 8$ (transient receptor potential cation channel, subfamily M, member 8) is expressed by

49 sensory neurons, and it is involved in the detection of cold temperatures. Increased TRPM8

50 activity triggers an increase in uncoupling protein 1 (Ucpl)-dependent brown adipose tissue

51 (BAT) thermogenesis. Bone density and marrow adipose tissue are regulated by rodent housing

52 temperature and brown adipose tissue, suggesting one mediator of this effect may be TRPM8. In

53 order to test whether TRPM8 was involved in the co-regulation of thermogenesis and bone

54 homeostasis, we examined the bone phenotypes of one-year-old $\operatorname{Trpm} 8$ knockout mice $(\operatorname{Trpm} 8$ -

$55 \mathrm{KO}$ ) and then exposed them to a 4-week cold temperature challenge. Male Trpm8-KO mice had

56 lower bone mineral density than WT, with smaller bone size (femur length and cross-sectional

57 area) being the most striking finding, and exhibited a delayed cold acclimation with increased

58 BAT expression of Ucp1, Dio2 and Cidea at the end of the study. In contrast to males, female

59 Trpm8-KO mice had low vertebral bone microarchitectural parameters, but no genotype-specific

60 alterations in body temperature. Interestingly, $\operatorname{Trpm} 8$ was not required for cold-induced

61 trabecular bone loss in either sex, but may be required for cold-induced changes in marrow

62 adiposity in males. Furthermore, bone marrow adipose tissue accumulation in females was

63 significantly blunted by Trpm 8 deletion. In summary, we identified sex differences in the role of

64 TRPM8 in maintaining body temperature, bone density and marrow adipose tissue. Identifying

65 mechanisms through which cold temperature and brown adipose tissue influence bone could help

66 to ameliorate potential bone side effects of obesity treatments designed to stimulate

67 thermogenesis. 


\section{Introduction}

Maintaining body temperature homeostasis involves both the regulation of heat loss and generation of heat (i.e. thermogenesis). Mammals require energy to generate and/or conserve

73 heat when in temperatures below their thermoneutral zone, which is room temperature in

74 humans, and warmer $\left(28-32^{\circ} \mathrm{C}\right)$ in mice [1]. During adaptation to cooler temperatures, sympathetic nervous system (SNS) output increases, elevating energy expenditure, fat oxidation, and heat production by brown adipose tissue (BAT). Uncoupling protein $1(U c p l)$ in the inner mitochondrial membrane of BAT generates heat by uncoupling oxidative phosphorylation from ATP production [2,3]. In addition to this, cold exposure can also trigger white adipose tissue (WAT) beiging to enhance heat production [4]. Previous studies have demonstrated a relationship between SNS activity and the skeleton, revealing that sympathetic outflow is not only involved in the activation of BAT thermogenesis for thermoregulation purposes, but that sympathetic tone can also suppress bone formation by signaling through the $\beta 2$-adrenergic receptor $(\beta 2 \mathrm{AR})$ expressed by osteoblasts [11][12]. Marrow adipocytes and osteoblasts have a common mesenchymal precursor and are known to be elevated in many conditions of low bone

85 density. However, the SNS suppresses both bone formation and bone marrow adipose tissue (BMAT), and a four-week cold exposure in on-year-old C3H/HeJ mice leads to reduced BMAT

87 at the most active sites of bone remodeling [13]. In that study, however, bone parameters were largely unchanged, and there was no indication of whether C57BL/6J mice (a commonly used model for skeletal research) would have bone loss from cold exposure. A more recent study,

90 however, showed that thermoneutral $\left(32^{\circ} \mathrm{C}\right)$ housing in $\mathrm{C} 57 \mathrm{BL} / 6 \mathrm{~J}$ mice exerted a protective

91 effect on the rodent skeleton, and this was associated with reduced expression of the $U c p l$ in

92 BAT [1]. These findings suggest that long-term cold-stimulus may be detrimental to bone 
93 density, but it is unclear what particular thermoregulatory pathways may promote bone and

94 marrow adipose tissue loss.

Transient receptor potential melastatin 8 (TRPM8) is a $\mathrm{Ca}^{2+}$ permeable, non-selective

96 cation channel expressed by temperature-sensing sensory neurons and is known to be the

97 principal detector of innocuous cold [14]. In mice, TRPM8 is activated by a wide temperature

98 range, approximately between $28^{\circ} \mathrm{C}$ to $8^{\circ} \mathrm{C}$, and also by cooling agents (e.g. menthol and icilin)

99 [15]. Previously, TRPM8 was primarily described to work as a peripheral thermal sensor;

100 however, there is evidence that this cold-sensing channel is also involved in thermoregulation by

101 promoting heat conservation and energy homeostasis [16]. Furthermore, TRPM8 is a potential

102 target for obesity treatment due to its function in regulating energy metabolism [16-21]. TRPM8

103 has been found to trigger non-shivering thermogenesis by BAT and the beiging of WAT in mice

104 [21][22] and humans [19]. Moreover, Trpm8 knockout (Trpm8-KO) mice are hyperphagic and

105 have reduced fat oxidation when housed at $21^{\circ} \mathrm{C}$, promoting the development of obesity [16].

106 However, it is unknown whether TRPM8 has a role in regulating bone density in vivo and by

107 inference, whether modulation of TRPM8 by obesity therapeutics might influence bone.

We hypothesized that Trpm8 deletion would impair body temperature regulation but may protect

112 male and female WT and Trpm 8 knockout $(\mathrm{KO})$ mice to a cold housing $\left(4^{\circ} \mathrm{C}\right)$ treatment and

113 examined body temperature, peripheral and marrow adipose tissue, bone microarchitecture and

114 remodeling. We found that male Tprm8-KO mice had impaired temperature regulation while

115 females did not. Male Trpm8-KO mice had a more overt low bone density phenotype, but 
116 females also had reduced microarchitectural parameters in cortical bone of the femur and

117 trabecular bone of the vertebrae. Overall, cold temperature reduced trabecular bone volume

118 fraction in males, while reducing cortical area fraction in females, but these effects were not

119 dependent upon genotype. Surprisingly, bone marrow adiposity was lower in Trpm8-KO females

120 compared to WT, but there was no striking effect of cold on either genotype or sex of mice, with

121 the exception of an interaction suggesting TRPM8 may be require for BMAT loss after cold in

122 males. There were, however, sex and genotype specific effects on the utilization of peripheral

123 adipose tissue stores, suggesting TRPM8 regulates the energy demands of thermogenesis in a

124 sex-dependent manner.

\section{Materials and Methods}

Jackson Laboratory (stock \#008198). Mice were bred and housed in a barrier animal facility at

Maine Medical Center Research Institute (MMCRI) on a 14-hr light and 10-hr dark cycle. Mice

were aged to 52 weeks while being housed up to four animals per cage at $22^{\circ} \mathrm{C}$. Mice were given

131 water and regular chow ad libitum. All animal protocols in this study were approved by the

132 Institutional Animal Care and Use Committee (IACUC) of MMCRI, an Association for

133 Assessment and Accreditation of Laboratory Animal Care (AAALAC)-accredited facility.

134 Euthanasia was performed using isoflurane followed by cervical dislocation or decapitation.

\section{Dual-energy X-ray absorptiometry (DXA)}

All mice had body weight measured prior to DXA. Areal bone mineral content (aBMC),

138 bone mineral density (aBMD), lean mass and fat mass measurements were performed on each 
mouse by a PIXImus dual energy X-ray densitometer (GE Lunar, GE Healthcare). The PIXImus was calibrated daily with a mouse phantom provided by the manufacturer. Mice were ventral side down with each limb and tail positioned away from the body. Full-body scans were obtained, and the head was excluded from analyses because of concentrated mineral content in skull and teeth. DXA data were processed and analyzed with Lunar PIXImus 2 (version 2.1) software [23]. Adiposity index was defined as fat mass divided by fat-free mass.

\section{Cold exposure Study}

Fifty-two week-old WT and Trpm8-KO mice were separated into individual cages. Half of the mice were maintained at room temperature, while the other half were moved to a cold room with automatic lights set to a $14 \mathrm{hr}$ light, $10 \mathrm{hr}$ dark cycle, equivalent to the light schedule of room temperature mice. Light intensity was not measured, but was comparable to that in the barrier animal facility and the source of the light was at the ceiling. Cold-treated mice were acclimatized to $18^{\circ} \mathrm{C}$ for 1 week, then $4^{\circ} \mathrm{C}$ for 3 weeks. This method of cold-temperature exposure has been previously published to produce changes in marrow adipose tissue $\mathrm{C} 3 \mathrm{H} / \mathrm{HeJ}$ mice and in $\mathrm{C} 57 \mathrm{BL} / 6 \mathrm{~J}$ mice as well as used to determine dependence of cold-acclimation on energy expenditure in mice [13][24]. Rectal temperature was measured daily in cold room mice and every 2 hours on the day of change to $4{ }^{\circ} \mathrm{C}$ with a Type $\mathrm{T}$ thermocouple rectal probe (RET-3, Physitemp Instruments, Inc., Clifton, NJ, USA) with a MicroTherma 2T hand-held thermometer (ThermoWorks, Inc., Lindon, UT; cat. no. THS-227-193). Cages contained standard bedding. Mice were fed regular chow and water ad libitum. Environmental temperature and humidity was measured and recorded daily. Mice were monitored for signs of pain and distress twice per day and every 2 hours on the day of change to $4^{\circ} \mathrm{C}$. We monitored and recorded any of the following 
162 signs: shivering, hunched posture, reduced mobility, ruffled fur and vocalization. Signs that were

163 found included occasional shivering and ruffled fur, and these generally resolved immediately if

164 not associated with low core temperature. If core temperature fell below $30^{\circ} \mathrm{C}$, mice were

165 immediately removed to room temperature and euthanized. No mice exhibited temperatures

166 below this threshold or exhibited signs of distress during the transition from $18^{\circ} \mathrm{C}$ to $4^{\circ} \mathrm{C}$. During

167 the $4^{\circ} \mathrm{C}$ period, two mice (one male $+/+$ and one male -/-) exhibited a low body temperature and

168 were immediately euthanized. No mice died spontaneously.

\section{Histology}

Femur and all adipose tissue samples were placed in $10 \%$ neutral buffered formalin

172 (Sigma-Aldrich) for $48 \mathrm{hr}$ and then stored in $70 \%$ ethanol. Bones were decalcified with EDTA

173 and bone and adipose tissue samples were paraffin embedded and tissues sections of $5 \mu \mathrm{m}$ were

174 deparaffinized and dehydrated in a graded series (100-70\%) of ethanol washes and stained with

175 hematoxylin and eosin (H\&E). Photomicrographs of H\&E stained tissues were taken at 4x

176 magnification.

\section{Bone Marrow Adipocyte Quantification and Analysis}

A blinded analysis of bone marrow (BM) adipocytes was performed on each histology

181 pixels/mm based on the microscope imaging objective and settings. The tissue area (T.Ar) was selected in the distal femoral metaphysis $(0.1 \mathrm{~mm}$ below the epiphyseal growth plate) using the 
185

186

187

188

189

190

191

192

193

194

195

196

197

198

199

200

201

202

203

204

205

206

207

to normalize adipocyte numbers per T.Ar for each image. Color images were converted to 32-bit and then thresholded using the Huang filter at the automatic level determined by ImageJ $[25,26]$. [Note: thresholding an image converts it to black (255) and white (0) values [25,26]. Images were then processed with the Despeckle and Adjustable Watershed plugins. [Despeckle was used to automatically remove salt-and-pepper background noise that could cause inaccuracies with particle analysis, while the Adjustable Watershed ImageJ segmentation algorithm was used to systematically correct any adjacent adipocytes that had been merged into 1, back into 2 distinct objects. ImageJ typically applies a watershed segmentation threshold at a level of 0.5 , but with the Adjustable Watershed the amount of segmentation can be changed to correct for closely packed adipocyte, tissue tears, or staining inconsistencies $[25,26]$. A blinded investigator set the Adjustable Watershed within the range of 0.3-0.8 to select the most appropriate segmentation threshold to apply to each image based solely on the quality of the individual image. Next, particle analysis for BM adipocytes was performed within the T.Ar using the Analyze Particles plugin. This plugin scans a selected area and measures objects that meet parameters based on area and circularity $[25,26]$. The particle circumference range was set to 50-2500 pixels (area results displayed in $\mathrm{mm}^{2}$ due to the set global scale) and the circularity was set at 0.60-1.00 (1.00 being a perfect circle). These parameters were determined through an iterative, trial and error analysis of different images until a universal measurement system was decided upon and then used for every image. After particle analysis, the Result and Summary pop-up windows provided the individual and average area $\left(\mathrm{mm}^{2}\right)$ for each counted adipocyte within the T.Ar; these data were used to quantify adiposity in each sample (based on adipocyte number and average adipocyte area). 


\section{Micro-computed tomography $(\mu \mathrm{CT})$}

A high-resolution desktop micro-tomographic imaging system ( $\mu$ CT40, Scanco Medical AG, Brüttisellen, Switzerland) was used to assess trabecular bone architecture in the distal femoral metaphysis and L5 vertebral body and cortical bone morphology of the femoral middiaphysis. Scans were acquired using a $10 \mu \mathrm{m}^{3}$ isotropic voxel size, $70 \mathrm{kVP}, 114 \mu \mathrm{A}, 200 \mathrm{~ms}$ integration time, and were subjected to Gaussian filtration and segmentation. Image acquisition and analysis protocols adhered to guidelines for the assessment of rodent bones by $\mu \mathrm{CT}$ [27]. In the femur, trabecular bone microarchitecture was evaluated in a $1500 \mu \mathrm{m}$ (150 transverse slices) region beginning $200 \mu \mathrm{m}$ superior to the peak of the growth plate and extending proximally. In the L5 vertebral body, trabecular bone was evaluated in a region beginning $100 \mu \mathrm{m}$ inferior to the cranial end-plate and extending to $100 \mu \mathrm{m}$ superior to the caudal end-plate. The trabecular bone regions were identified by manually contouring the endocortical region of the bone.

Thresholds of $335 \mathrm{mgHA} / \mathrm{cm}^{3}$ and $385 \mathrm{mgHA} / \mathrm{cm}^{3}$ were used to segment bone from soft tissue in the femur and L5 vertebrae, respectively. The following architectural parameters were measured using the Scanco Trabecular Bone Morphometry evaluation script: trabecular bone volume fraction (Tb.BV/TV, \%), t rabecular bone mineral density (Tb. BMD, $\mathrm{mgHA} / \mathrm{cm}^{3}$ ), specific bone surface $\left(\mathrm{BS} / \mathrm{BV}, \mathrm{mm}^{2} / \mathrm{mm}^{3}\right)$, trabecular thickness $(\mathrm{Tb} . \mathrm{Th}, \mathrm{mm})$, trabecular number $\left(\mathrm{Tb} . \mathrm{N}, \mathrm{mm}^{-1}\right.$ ), and trabecular separation (Tb.Sp, mm), connectivity density (Conn.D, $1 / \mathrm{mm}^{3}$ ). Cortical bone was assessed in 50 transverse $\mu \mathrm{CT}$ slices (500 $\mu \mathrm{m}$ long region) at the femoral mid-diaphysis and the region included the entire outer most edge of the cortex. Cortical bone was segmented using a fixed threshold of $708 \mathrm{mgHA} / \mathrm{cm}^{3}$. The following variables were computed: total cross-sectional area (bone + medullary area) $\left(\mathrm{Tt} . \mathrm{Ar}, \mathrm{mm}^{2}\right)$, cortical bone area $\left(\mathrm{Ct} . \mathrm{Ar}, \mathrm{mm}^{2}\right)$, medullary area (Ma.Ar, $\mathrm{mm}^{2}$ ), bone area fraction (Ct.Ar/Tt.Ar, \%), cortical tissue mineral density (Ct.TMD, 
$\left.231 \mathrm{mgHA} / \mathrm{cm}^{3}\right)$, cortical thickness (Ct.Th, mm), cortical porosity (\%), as well as bone strength

232 indicators such as maximum, minimum and polar moments of inertia $\left(I_{\max }, I_{\min }\right.$, and pMOI,

$233 \mathrm{~mm}^{4}$ ), which describe the shape/distribution of cortical bone (larger values indicate a higher

234 bending strength). Cortical bone images were taken of the mouse using the median total area

235 value within each group. The scale for all of the images is $1 \mathrm{~mm}$ equals 315 pixels.

Real-time PCR

Adipose tissues (brown and gonadal adipose tissue) were collected from WT and Trpm8-

$K O$ mice for RNA extraction under liquid nitrogen conditions. Total RNA was prepared using

243 Green Supermix with a BioRad ${ }^{\circledR}$ Laboratories CFX Connect Real-time System thermal cycler 244 and detection system. TATA binding protein 1 (Tbp1) was used as an internal standard control 245 gene for all quantification [28]. Primers used were from Integrated DNA Tecnologies (IDT)

246 (Coralvile, IA) [29-31] and Primer Design (Southampton, UK). All primer sequences are listed 247 in Supplementary Table I.

248 Supplemental Table I. qPCR primer information.

\begin{tabular}{llll}
\hline Gene & Source & Sequence & Reference \\
\hline Acadl & Primer & For: 5'-GGA ATG AAA GCT CAG GAC ACA -3' & N/A \\
& Design & Rev: 5'-AGC CTT TAT TCT CTT CTC CAA GT -3' & \\
Cidea & IDT & For: 5'-TGC TCT TCT GTA TCG CCC AGT -3' & Seale et al. \\
& & Rev: 5'-GCC GTG TTA AGG AAT CTG CTG -3' & (2008) \\
Dio2 & IDT & For: 5'-CAG TGT GGT GCA CGT CTC CAA TC -3' & Cooper et al. \\
& & Rev: 5'-TGA ACC AAA GTT GAC CAC CAG -3' & (2008)
\end{tabular}




$\begin{array}{llll}\text { Pdk4 } & \text { Primer } & \text { For: 5'-AAA GTG GGT CTG TGG CAT TG -3' } & \text { N/A } \\ & \text { Design } & \text { Rev: 5'-AAG GTT TGT ACT CGT GTT TGT G -3' } & \\ \text { Pparcla } & \text { IDT } & \text { For: 5'- TGA TGT GAA TGA CTT GGA TAC AGA CA -3' } & \text { Cooper et al. } \\ & & \text { Rev: 5'- GCT CAT TGT TGT ACT GGT TGG ATA TG -3' } & \text { (2008) } \\ \text { Ppary2 } & \text { IDT } & \text { For: 5'-GCA TGG TGC CTT CGC TGA -3' } & \text { Cooper et al. } \\ & & \text { Rev: 5'-TGG CAT CTC TGT GTC AAC CAT G -3' } & \text { (2008) } \\ \text { Prdm16 } & \text { IDT } & \text { For: 5'-CAG CAC GGT GAA GCC ATT C -3' } & \text { Cooper et al. } \\ & & \text { Rev: 5'-GCG TGC ATC CGC TTG TG -3' } & \text { (2008) } \\ \text { Tbp1 } & \text { IDT } & \text { For: 5'-GAA GCT GCG GTA CAA TTC CAG -3' } & \text { Sanchez- } \\ & & \text { Rev: 5'-CCC CTT GTA CCC TTC ACC AAT -3' } & \text { Gurmaches } \\ & & & \\ & & & \end{array}$

N/A: not applicable. 


\section{Statistical analysis}

Data are presented as mean \pm standard error. Student's $t$ test or two-way ANOVA was performed with Holm-Sidak post hoc multiple comparison test as needed. $p<0.05$ was considered statistically significant.

Results

Body composition and two-dimensional areal bone density (n=14-19/group) were assessed at 52 weeks of age in mice housed at standard room temperature $\left(22^{\circ} \mathrm{C}\right)$ (Figure 1). Both male and female Trpm8-KO mice had reduced body mass compared to WT mice, which was in part due to a significant reduction in lean mass in males (Figure 1A,B). In both sexes, two-way ANOVA indicated that Trpm 8 deletion significantly affected fat mass and $\%$ body fat, but in pairwise comparisons, only female \% body fat was lower after Trpm 8 deletion (Figure mineral content $(\mathrm{BMC})$ parameters (Figure 1E,F). In the latter, there was a significant interaction between sex and genotype such that $\operatorname{Trpm} 8$ deletion caused significantly lower bone mineral content in males, but not in females (Figure 1F).

Figure 1. Trpm8 deletion causes reduced body mass, lean mass and bone density in male mice. (A-D) Body composition in 52-week old male (blue) and female (purple), wildype (closed circles) and Trpm8-KO (open squares) mice was analyzed by DXA. (E,F) Areal total body bone mineral density (aBMD) and areal bone mineral content (BMC) were measured excluding the head. Data are expressed as individual points with bars representing mean \pm SEM. Tables below each panel indicate results of the two-way ANOVA, with $p$-values for sex, genotype and their significance. 
Trpm8-KO mice had significantly lower femur total cross-sectional area (total area) and lower

in females. Polar moment of inertia (an indicator of strength), was dependent upon genotype

2G). Other parameters, such as cortical tissue mineral density, cortical thickness and porosity

were not dependent upon genotype (Figure 2F,H-J). However, femur length was shorter in male

were a result of altered trabecular microarchitecture, we performed $\mu \mathrm{CT}$ on the distal femur

content and density.

Figure 2. Trpm8 deletion reduced femur size in male mice. Femurs from room temperature housed male and female Trpm8-KO and WT mice were scanned by $\mu \mathrm{CT}$. (A,B) Representative images of the femur cross section from the midshaft, where cortical microarchitectural measurements were performed (C-J). Shaded areas of the pictograms in C-D represent the region of interest for each measurement. Data are expressed as individual points with bars representing mean \pm SEM. Tables below each panel indicate results of the two-way ANOVA, with $p$-values for sex, genotype and their interaction. $p$-values above the bars represent results from HolmSidak post hoc test for pairwise significance.

\section{Figure 3. Trpm8 deletion did not overtly impact trabecular microarchitecture of the distal} femur. Bone volume fraction (BV/TV) of the trabecular bone of the distal femur was measured in male and female Trpm8-KO and WT mice. Data are expressed as individual points with bars representing mean \pm SEM. Table below the panel indicate results of the two-way ANOVA, with $p$-values for sex, genotype and their interaction. $p$-values above the bars represent results from Holm-Sidak post hoc test for pairwise significance. 
Previous studies have demonstrated that TRPM8 regulates brown adipose tissue function,

and thermogenesis has been associated with changes in trabecular bone remodeling [12,22,23].

We next wanted to test, 1) whether a 4-week cold exposure would lead to trabecular bone loss and 2) whether TRPM8 was necessary for the adipose tissue and bone responses to cold (Figure 4A). Mice were separated into individual cages and then left at room temperature or moved to $18^{\circ} \mathrm{C}$ (Figure $\left.4 \mathrm{~A}\right)$. After one week, the temperature was changed from $18^{\circ} \mathrm{C}$ to $4^{\circ} \mathrm{C}$. Male $\operatorname{Trpm} 8$ $K O$ mice had a poorer response to the cold challenge than WT, with core temperature being lower in the $\mathrm{KO}$ (Figure 4B). Interestingly, the impact of housing temperature change on female mouse core temperature was not dependent upon genotype. By the end of week 2, male $\operatorname{Trpm} 8$ $K O$ mice had acclimated to the cold exposure and reached core temperatures similar to those of male WT mice (Figure 4C) which was maintained until the endpoint of the study.

Figure 4. Male Trpm8-KO mice had lower core temperature during acclimatization to cold. (A) At 52 weeks of age, mice were separated into individual cages and half were kept at room temperature while the other half were moved to a cold room set at $18^{\circ} \mathrm{C}$. After one week, the temperature was changed to $4^{\circ} \mathrm{C}$ and mice were maintained for 3 additional weeks. (B) During the temperature change from $18^{\circ} \mathrm{C}$ to $4^{\circ} \mathrm{C}$, core temperature was measured every 2 hours. (C) Weekly core temperature, starting from time zero before mice were moved into the cold, and including the data from the 8 hour time point of the day the temperature changed from $18^{\circ} \mathrm{C}$ to $4^{\circ} \mathrm{C}$. (D) Percent change in body weight. Temperature data points represent mean \pm SEM. Body weight data are expressed as individual points with bars representing mean \pm SEM. Table below panels B and D indicate results of the two-way ANOVA (performed using data from $8 \mathrm{hr}$ time point in $\mathrm{B}$ ), with $p$-values for sex, genotype and their interaction.

Previous studies had shown that impaired BAT function in response to cold was associated with bone loss. Therefore, we next wanted to identify changes in brown adipose tissue with cold treatment. Cold exposure induced BAT expansion in male WT and Trpm8-KO mice $(\mathrm{p}<0.05)$ (Figure 5A). In contrast, the expansion of BAT mass in female mice was observed only 
in the WT group ( $\mathrm{p}=0.002$ ) in response to cold, but not in female Trpm8-KO mice. In H\&E stained sections of BAT, we observed larger lipid droplets in BAT from males of all genotypes and treatments, as well as in female $\operatorname{Trpm} 8-\mathrm{KO}$ mice at room temperature. Other female groups had less lipid accumulation, including in the female Trpm8-KO mice after cold. We also observed that cold treatment increased Ucpl gene expression in BAT from male WT mice, but the level of Ucpl expression was not different between cold treated WT and Trpm8-KO at either temperature. Overall, KO cold-treated mice had elevated expression of other fatty acid metabolism markers (Acadl, Prdm16, and Pparc1 $\alpha$ ) and thermogenic markers (Cidea and Dio2)

(Figure 5C). Changes in BAT gene expression were less striking in females compared to males, with the notable exceptions of cold treatment inducing $U c p l$ to a greater degree in the $\mathrm{KO}$ females than in the WT females and suppressing PParg2 in both genotypes (Figure 5C).

347 Together, these results indicate Trpm8 regulates the BAT response to temperature change in 348 males and females.

Figure 5. TRPM8 regulates the response of BAT to cold temperature. (A) BAT weights from male and female WT and Trpm $8-\mathrm{KO}$ housed at $22^{\circ} \mathrm{C}$ and $4^{\circ} \mathrm{C}$. (B) Representative $\mathrm{H} \& \mathrm{E}$ stained image of BAT. N=5-8. (C) Gene expression of fatty acid metabolism and thermogenic markers in male (top) and female (bottom) BAT. Data presented as mean \pm standard error. ${ }^{*} \mathrm{p}<0.05$ and ** $\mathrm{p}<0.01$ by Holm-Sidak post doc test after a significant two-way ANOVA. 
TRPM8 regulates the acclimatization to cold. These findings were supported by gene expression in gWAT in female mice, which showed, among other things, a 5 to 8 -fold increase in Ucp1 expression after cold, while the male mice only had a 2- and 4-fold increase in WT and KO, respectively, after cold treatment (Figure 6C). Similarly, female mice also had significant increases in Acadl, Pparcla, Pdk4, Cidea and Dio2 in the cold, whereas males did not have any other changes (Figure 6C). Taken together, these data indicate TRPM8 may be required for beiging of gWAT tissue in males but not females. Further, females may be more prone to generate beige adipocytes in gWAT than males, which could explain their advantage over males in adjusting to cold temperature.

Figure 6. Loss of Trpm8 prevented beige adipocyte formation in gonadal adipose tissue from male but not female mice. (A) gWAT weights from male and female WT and Trpm8-KO housed at $22^{\circ} \mathrm{C}$ and $4^{\circ} \mathrm{C}$. (B) Representative H\&E stained image of gWAT. (C) Gene expression of fatty acid metabolism and thermogenic markers in male (top) and female (bottom) gWAT. Data presented as mean \pm standard error. ${ }^{*} \mathrm{p}<0.05$ and $* * \mathrm{p}<0.01$ by Holm-Sidak post doc test after a significant two-way ANOVA.

Because altered thermogenesis has previously been associated with changes in bone homeostasis, we next examined bone microarchitectural phenotypes of WT and Trpm8-KO mice at room temperature and with cold exposure. In addition to cortical bone changes due to genotype and sex noted above in mice at room temperature (Figure 2), we determined that cold temperature caused trabecular bone loss (decreased BV/TV) in male mice of both gentoypes, in both the femur and the vertebrae (Table I). However, cold temperature treatment did not influence cortical bone in either genotype of male mice. In contrast to males, females had only had increased L5 trabecular BS/BV (indicative of trabecular thinning) in response to cold, but no changes in BV/TV in either the femur or the vertebral trabecular bone (Table II). Medullary area 
388 was increased with cold, leading to a reduction in cortical area fraction in females (Table II).

389 However, there were no significant temperature by genotype interactions in trabecular or cortical

390 bone parameters in either sex, suggesting bone loss from cold was not dependent upon TRPM8

391 in males or females (Tables I and II). Of note, female, but not male, mice also had reduced

392 vertebral trabecular microarchitectural parameters after $\operatorname{Trpm} 8$ deletion (Table II), but this was

393 also not dependent upon housing temperature. 
Table I. Femoral and Vertebral Bone outcomes assessed by $\mu \mathrm{CT}$ of Male wildtype (WT) and Trpm8-Knockout (KO) mice housed at

\begin{tabular}{|c|c|c|c|c|c|c|c|}
\hline & \multicolumn{2}{|c|}{ Room temperature $\left(22^{\circ} \mathrm{C}\right)$} & \multicolumn{2}{|l|}{ Cold $\left(4^{\circ} \mathrm{C}\right)$} & \multicolumn{3}{|l|}{$p$-value } \\
\hline & WT & $\mathrm{KO}$ & WT & $\mathrm{KO}$ & genotype & temp & interaction \\
\hline \multicolumn{8}{|c|}{ Distal Femur Trabecular Bone } \\
\hline BV/TV (\%) & $11.1 \pm 0.8$ & $11.9 \pm 0.9$ & $8.9 \pm 1.0$ & $9.9 \pm 1.1$ & 0.36 & 0.04 & 0.91 \\
\hline Conn.D $\left(1 / \mathrm{mm}^{3}\right)$ & $43 \pm 7$ & $58.5 \pm 9.0$ & $31.2 \pm 5.8$ & $43.1 \pm 7.3$ & 0.07 & 0.08 & 0.79 \\
\hline Tb.N (1/mm) & $3.0 \pm 0.1$ & $3.2 \pm 0.1$ & $2.8 \pm 0.1$ & $3.0 \pm 0.1$ & 0.07 & 0.06 & 0.67 \\
\hline Tb.Th (mm) & $0.059 \pm 0.001$ & $0.061 \pm 0.003$ & $0.058 \pm 0.002$ & $0.056 \pm 0.002$ & 0.95 & 0.15 & 0.19 \\
\hline Tb.Sp (mm) & $0.323 \pm 0.017$ & $0.304 \pm 0.007$ & $0.347 \pm 0.007$ & $0.321 \pm 0.011$ & 0.07 & 0.09 & 0.78 \\
\hline \multicolumn{8}{|c|}{ Femur Midshaft Cortical Bone } \\
\hline Ct.Th (mm) & $0.159 \pm 0.007$ & $0.161 \pm 0.008$ & $0.160 \pm 0.006$ & $0.154 \pm 0.004$ & 0.20 & 0.67 & 0.52 \\
\hline Ct.Ar $\left(\mathrm{mm}^{2}\right)$ & $0.88 \pm 0.04$ & $0.86 \pm 0.04$ & $0.88 \pm 0.03$ & $0.82 \pm 0.03$ & 0.26 & 0.49 & 0.52 \\
\hline Ct.TMD $\left(\mathrm{mgHA} / \mathrm{cm}^{3}\right)$ & $1195 \pm 7$ & $1197 \pm 5$ & $1198 \pm 8$ & $1192 \pm 5$ & 0.73 & 0.79 & 0.50 \\
\hline $\operatorname{Ma} . \operatorname{Ar}\left(\mathrm{mm}^{2}\right)$ & $1.77 \pm 0.10$ & $1.52 \pm 0.05$ & $1.74 \pm 0.11$ & $1.54 \pm 0.06$ & 0.01 & 0.97 & 0.81 \\
\hline Tt. $\operatorname{Ar}\left(\mathrm{mm}^{2}\right)$ & $2.64 \pm 0.09$ & $2.38 \pm 0.06$ & $2.62 \pm 0.12$ & $2.36 \pm 0.07$ & 0.005 & 0.77 & 0.99 \\
\hline Ct.Ar/Tt.Ar (\%) & $33.5 \pm 1.9$ & $36.2 \pm 1.5$ & $33.7 \pm 1.4$ & $34.8 \pm 0.9$ & 0.21 & 0.67 & 0.58 \\
\hline Ct. Porosity (\%) & $0.23 \pm 0.03$ & $0.26 \pm 0.03$ & $0.20 \pm 0.01$ & $0.23 \pm 0.02$ & 0.27 & 0.14 & 0.87 \\
\hline $\mathrm{pMOI}\left(\mathrm{mm}^{4}\right)$ & $0.64 \pm 0.04$ & $0.58 \pm 0.04$ & $0.64 \pm 0.04$ & $0.54 \pm 0.03$ & 0.04 & 0.63 & 0.72 \\
\hline $\operatorname{Imax}\left(\mathrm{mm}^{4}\right)$ & $0.42 \pm 0.03$ & $0.40 \pm 0.03$ & $0.42 \pm 0.03$ & $0.37 \pm 0.03$ & 0.19 & 0.53 & 0.67 \\
\hline $\operatorname{Imin}\left(\mathrm{mm}^{4}\right)$ & $0.22 \pm 0.01$ & $0.18 \pm 0.01 *$ & $0.22 \pm 0.02$ & $0.18 \pm 0.01 *$ & 0.0009 & 0.89 & 0.89 \\
\hline \multicolumn{8}{|c|}{ L5 Vertebral Trabecular Bone } \\
\hline BV/TV (\%) & $21.6 \pm 1.1$ & $20.7 \pm 1.8$ & $18.7 \pm 0.5$ & $18.4 \pm 0.7$ & 0.59 & 0.04 & 0.78 \\
\hline $\mathrm{BS} / \mathrm{BV}\left(\mathrm{mm}^{2} / \mathrm{mm}^{3}\right)$ & $43.9 \pm 1.5$ & $44.5 \pm 1.9$ & $46.2 \pm 0.4$ & $46.9 \pm 0.3$ & 0.62 & 0.08 & 0.95 \\
\hline $\mathrm{BMD}\left(\mathrm{mgHA} / \mathrm{cm}^{3}\right)$ & $226.4 \pm 10.0$ & $217.3 \pm 16.1$ & $198.2 \pm 4.7$ & $197.6 \pm 5.9$ & 0.65 & 0.03 & 0.69 \\
\hline
\end{tabular}




\begin{tabular}{lllllllll} 
Conn.D $\left(1 / \mathrm{mm}^{3}\right)$ & $127 \pm 11$ & $115 \pm 8$ & $113 \pm 5$ & $119 \pm 8$ & 0.73 & 0.53 & 0.32 & \\
Tb.N $(1 / \mathrm{mm})$ & $4.4 \pm 0.1$ & $4.3 \pm 0.1$ & $4.1 \pm 0.1$ & $4.2 \pm 0.1$ & 0.94 & 0.11 & 0.43 & \\
Tb.Th $(\mathrm{mm})$ & $0.050 \pm 0.001$ & $0.053 \pm 0.002$ & $0.050 \pm 0.003$ & $0.053 \pm 0.002$ & 0.10 & 0.96 & 0.96 \\
Tb.Sp $(\mathrm{mm})$ & $0.215 \pm 0.007$ & $0.223 \pm 0.009$ & $0.236 \pm 0.005$ & $0.230 \pm 0.009$ & 0.89 & 0.08 & 0.37 \\
\hline
\end{tabular}

${ }^{*} \mathrm{p}<0.05$ compared to WT mice group. $\mathrm{N}=6-7$. Abbreviations: BV/TV, bone volume fraction; Conn.D, connectivity density; Tb.N, trabecular number; Tb.Th, trabecular thickness; Tb.Sp, trabecular separation; Ct.Th, average cortical thickness; Ct.Ar, cortical bone area; Ct.TMD, cortical tissue mineral density; M.Ar, marrow area; T.Ar, total cross-sectional area; Ct.Ar/T.Ar, cortical area fraction; Ct.Porosity, cortical porosity; pMOI, polar moment of inertia; Imax, maximum moment of inertia; Imin, minimum moment of inertia; $\mathrm{BMD}$, bone mineral density; BS/BV, specific bone surface.

Table II. Femoral and Vertebral Bone outcomes assessed by $\mu \mathrm{CT}$ of Female wildtype (WT) and Trpm8-Knockout (KO) mice housed at room temperature or cold.

\begin{tabular}{|c|c|c|c|c|c|c|c|}
\hline & \multicolumn{2}{|c|}{ Room temperature $\left(22^{\circ} \mathrm{C}\right)$} & \multicolumn{2}{|l|}{ Cold $\left(4^{\circ} \mathrm{C}\right)$} & \multicolumn{3}{|l|}{$p$-value } \\
\hline & WT & $\mathrm{KO}$ & WT & $\mathrm{KO}$ & genotype & temp & interaction \\
\hline \multicolumn{8}{|c|}{ Distal Femur Trabecular Bone } \\
\hline $\mathrm{BV} / \mathrm{TV}(\%)$ & $2.13 \pm 0.38$ & $2.78 \pm 0.90$ & $1.87 \pm 0.20$ & $2.58 \pm 0.78$ & 0.32 & 0.73 & 0.97 \\
\hline Conn.D $\left(1 / \mathrm{mm}^{3}\right)$ & $4.3 \pm 1.4$ & $14.4 \pm 7.9$ & $6.6 \pm 1.7$ & $15.9 \pm 10.7$ & 0.21 & 0.81 & 0.96 \\
\hline Tb.N (1/mm) & $1.7 \pm 0.1$ & $1.8 \pm 0.1$ & $1.7 \pm 0.1$ & $1.8 \pm 0.1$ & 0.46 & 0.74 & 0.62 \\
\hline Tb.Th (mm) & $0.060 \pm 0.003$ & $0.056 \pm 0.003$ & $0.052 \pm 0.001$ & $0.054 \pm 0.003$ & 0.56 & 0.07 & 0.27 \\
\hline Tb.Sp (mm) & $0.611 \pm 0.039$ & $0.584 \pm 0.037$ & $0.588 \pm 0.027$ & $0.585 \pm 0.32$ & 0.67 & 0.74 & 0.72 \\
\hline \multicolumn{8}{|c|}{ Femur Midshaft Cortical Bone } \\
\hline Ct.Th (mm) & $0.188 \pm 0.007$ & $0.177 \pm 0.004$ & $0.177 \pm 0.004$ & $0.174 \pm 0.004$ & 0.16 & 0.16 & 0.42 \\
\hline Ct.Ar $\left(\mathrm{mm}^{2}\right)$ & $0.85 \pm 0.04$ & $0.78 \pm 0.02$ & $0.82 \pm 0.02$ & $0.78 \pm 0.02$ & 0.04 & 0.71 & 0.62 \\
\hline Ct.TMD $\left(\mathrm{mgHA} / \mathrm{cm}^{3}\right)$ & $1251 \pm 6$ & $1244 \pm 5$ & $1248 \pm 5$ & $1241 \pm 4$ & 0.16 & 0.55 & 0.93 \\
\hline $\operatorname{Ma} . \operatorname{Ar}\left(\mathrm{mm}^{2}\right)$ & $1.12 \pm 0.04$ & $1.05 \pm 0.03$ & $1.21 \pm 0.05$ & $1.14 \pm 0.03$ & 0.08 & 0.02 & 0.89 \\
\hline
\end{tabular}




$\begin{array}{llllllll}\text { Tt.Ar }\left(\mathrm{mm}^{2}\right) & 1.97 \pm 0.07 & 1.83 \pm 0.04 & 2.03 \pm 0.06 & 1.92 \pm 0.04 & \mathbf{0 . 0 2} & 0.14 & 0.81 \\ \text { Ct.Ar/Tt.Ar }(\%) & 43.1 \pm 1.2 & 42.6 \pm 1.0 & 40.7 \pm 0.9 & 40.7 \pm 0.8 & 0.80 & \mathbf{0 . 0 3} & 0.76 \\ \text { Ct. Porosity }(\%) & 0.19 \pm 0.01 & 0.21 \pm 0.02 & 0.21 \pm 0.01 & 0.24 \pm 0.03 & 0.28 & 0.26 & 0.86 \\ \text { pMOI }\left(\mathrm{mm}^{4}\right) & 0.44 \pm 0.04 & 0.37 \pm 0.02 & 0.44 \pm 0.02 & 0.37 \pm 0.03 & \mathbf{0 . 0 2} & 0.91 & 0.98 \\ \text { Imax }\left(\mathrm{mm}^{4}\right) & 0.29 \pm 0.03 & 0.24 \pm 0.01 & 0.28 \pm 0.02 & 0.25 \pm 0.01 & \mathbf{0 . 0 2} & 0.80 & 0.78 \\ \text { Imin }\left(\mathrm{mm}^{4}\right) & 0.15 \pm 0.01 & 0.13 \pm 0.01 & 0.16 \pm 0.01 & 0.15 \pm 0.01 & 0.05 & 0.33 & 0.65 \\ & & & & & & \\ \text { L5 Vertebral Trabecular } \text { Bone } & 15.8 \pm 1.2 & 13.1 \pm 0.5 & 14.2 \pm 1.2 & 12.0 \pm 0.5 & \mathbf{0 . 0 1} & 0.16 & 0.81 \\ \text { BV/TV }(\%) & 38.2 \pm 1.3 & 40.9 \pm 1.1 & 41.5 \pm 1.2 & 43.4 \pm 1.7 & 0.10 & \mathbf{0 . 0 4} & 0.77 \\ \text { BS/BV }\left(\mathrm{mm}^{2} / \mathrm{mm}^{3}\right) & 174 \pm 12 & 148 \pm 4 & 158 \pm 12 & 138 \pm 4 & \mathbf{0 . 0 2} & 0.15 & 0.80 \\ \text { BMD }\left(\mathrm{mgHA} / \mathrm{cm}^{3}\right) & 51 \pm 9 & 48 \pm 7 & 60 . \pm 7 & 48 \pm 8 & 0.36 & 0.55 & 0.57 \\ \text { Conn.D }\left(1 / \mathrm{mm}^{3}\right) & 2.67 \pm 0.07 & 2.43 \pm 0.12 & 2.68 \pm 0.11 & 2.44 \pm 0.09 & \mathbf{0 . 0 2} & 0.90 & 0.99 \\ \text { Tb.N }\left(1 / \mathrm{mm}^{3}\right) & 0.061 \pm 0.002 & 0.057 \pm 0.002 & 0.056 \pm 0.001 & 0.054 \pm 0.002 & 0.15 & 0.06 & 0.64 \\ \text { Tb.Th }(\mathrm{mm}) & 0.382 \pm 0.009 & 0.428 \pm 0.024 & 0.384 \pm 0.014 & 0.423 \pm 0.016 & \mathbf{0 . 0 2} & 0.90 & 0.83 \\ \text { Tb.Sp }(\mathrm{mm}) & & & & & & \end{array}$

${ }^{*} \mathrm{p}<0.05$ compared to WT mice group. $\mathrm{N}=8-11$. Abbreviations: BV/TV, bone volume fraction; Conn.D, connectivity density; Tb.N, trabecular number; Tb.Th, trabecular thickness; Tb.Sp, trabecular separation; Ct.Th, average cortical thickness; Ct.Ar, cortical bone area; Ct.TMD, cortical tissue mineral density; M.Ar, marrow area; T.Ar, total cross-sectional area; Ct.Ar/T.Ar, cortical area fraction; 
Finally, we also evaluated whether cold exposure and/or loss of Trpm8 would affect the adiposity of the bone marrow (Figure 7). In general, bone marrow adipose tissue (BMAT) is significant interaction between genotype and housing temperature $(\mathrm{p}=0.045)$ in the $\%$ total

417 adiposity, suggesting Trpm8-KO males do not lose marrow adipose tissue at cold temperatures,

418 while WT mice do (Figure 7D). In female mice, there was a significant effect of Trpm8 deletion

419 on adipocyte number (Figure 7E) and \% adiposity (Figure 7G), but not adipocyte size. In contrast to males, there was no clear impact of housing temperature on bone marrow adipose tissue females.

Figure 7. Trpm8 deletion suppressed marrow fat in female mice. (A and B) Representative room temperature $(\mathrm{RT})\left(22^{\circ} \mathrm{C}\right)$ and cold temperature $\left(4^{\circ} \mathrm{C}\right)$. $(\mathrm{C}$ and D) Quantification of adipocyte numbers (Ad.N/T.Ar), average adipocyte size (Ad.A), and \% adiposity (T.Ar Adiposity) within the bone marrow of male and female WT and Trpm 8 - $K O$ mice housed at $22^{\circ} \mathrm{C}$

\section{Discussion} and $4^{\circ} \mathrm{C}$. (E and F) Representative $\mathrm{H} \& \mathrm{E}$ stained image of distal femur area from male and female WT and Trpm8-KO mice housed at $22^{\circ} \mathrm{C}$ and $4{ }^{\circ} \mathrm{C}$ (scale bar: $500 \mu \mathrm{m}$; magnification: $4 \mathrm{x}$ ). Data presented as mean \pm standard error. and adipose tissue was dependent upon sex and housing temperature (Table IV summary). Our original hypothesis was that Trpm8 deletion would impair body temperature regulation, but would also protect against cold-induced changes in bone and marrow adipose tissue. Males, but not females, had impaired temperature regulation after $\operatorname{Trpm} 8$ deletion. However, cold housing

438 led to trabecular bone loss in males and cortical bone loss in females, independent of genotype, 
BMAT [32], and our findings indicate that in males this may be dependent upon Trpm8 (Figure

Table IV. Summary of results.

\begin{tabular}{|c|c|c|c|c|}
\hline & \multicolumn{2}{|l|}{ Males } & \multicolumn{2}{|l|}{ Females } \\
\hline & Trpm8 Deletion & Cold Housing & Trpm8 Deletion & Cold Housing \\
\hline Body Temperature & \multicolumn{4}{|c|}{$\begin{array}{l}\text { Sex by genotype interaction - temperature reduced in male KOs but not female } \\
\text { KOs in cold }\end{array}$} \\
\hline Bone Size & decreased & uc & $\mathrm{uc}$ & uc \\
\hline Cortical Bone & uc & uc & $\mathrm{uc}$ & decreased \\
\hline Trabecular Bone & $\mathrm{uc}$ & decreased & decreased (L5 only) & uc \\
\hline Marrow Adiposity & \multicolumn{2}{|c|}{ Genotype by temp interaction } & decreased & $\mathrm{uc}$ \\
\hline
\end{tabular}

Abbreviation: uc, unchanged.

A bone phenotype in Trpm8-KO mice has not been previously described. Bone size was smaller in male Trpm8-KO mice compared to WT, but this difference did not occur in females. Furthermore, female mice had significant trabecular bone loss in the vertebrae but not the femur, indicating potential site-specific effects of Trpm8 deletion on bone. Recently, Iwaniec et al.

456 (2016) highlighted that the current standard room temperature housing $\left(22^{\circ} \mathrm{C}\right)$ can already be 457 considered a cold environment to mice and that it was associated with bone loss in growing 458 females compared to thermoneutral housing [1]. A Trpm8 functional cold circuit is established 459 after birth around postnatal day 14 [33]. Others have found that Trpm8 is a regulator of energy 
460

461

462

463

464

465

466

467

468

469

470

471

472

473

474

475

476

477

478

479

480

481

482

metabolism and thermogenesis [16,19,21], and our findings are consistent: showing that its deletion can cause an increase in the expression of thermogenic markers, gWAT fat pad reduction and weight loss. This suggests that the absence of Trpm 8 during the developmental phase might be associated with defective cold circuits which partially fail to sustain optimal body temperature, as previously described [16]. Thus, it is plausible that the lack of Trpm8 during growth causes a shift towards energy utilization for heat generation, decreasing ATP availability for bone cells, leading to altered bone density. However, the mechanism of low bone mass in Trpm8-KO mice, and the relative contributions of bone forming osteoblasts and bone resorbing osteoclasts, are yet to be determined. Some in vitro evidence suggests human osteoblast-like cells and murine osteoblast cells express $\operatorname{Trpm} 8$, but the functional impact on bone is unclear [34]. Although the deletion of other Trp channels, such as Trpv1 [35] and Trpv5 [36], has been reported to induce bone loss in animal models, there is a lack of data exploring the physiological role of TRPM8 in skeletal homeostasis.

One interesting finding was that Trpm 8 deletion in females caused decreased BMAT content. Aging generally leads to accumulation of bone marrow adipose tissue in the distal femur and proximal tibia in mice, but the mechanisms and consequences of this accumulation remain an area of active investigation. Both osteoblasts and adipocytes arise from a shared mesenchymal precursor, thus one hypothesis is that situations of bone loss may lead to marrow adiposity by shunting cells away from the osteoblast lineage to the adipocyte lineage (as in calorie restriction, PPARg2 inhibition, and aging). However, the alternate, shifting from marrow adipose lineage to osteoblast lineage, does not seem likely, since female Trpm8-KO mice had indices of reduced bone density in concert with low marrow adiposity. In other situations, like bone loss from the atypical antipsychotic drug risperidone, elevated SNS activity leads to a reduction in both 
osteoblast-mediated bone formation and marrow adiposity as well as increased expression of deletion.

Investigations into sex differences in the thermogenic response to Trpm 8 deletion have

498 activates Ucp-1 dependent thermogenesis and increases core temperature in WT mice, but that

499 when TRPM8 is deleted, this activation is absent [22]. In contrast, our studies use cold-

500 temperature to induce thermogenesis, and show a partial dependence on TRPM8. However, our

501 findings also indicate that other pathways may compensate for the loss of TRPM8, especially in

502 the females. Specifically, Trpm8-KO male mice struggled to increase body temperature to the

503 level of WT in a cold environment (of which, menthol treatment is partly mimicking). However,

504 the study by Ma, et al. (2012) did not directly compare WT to KO body temperature, so it is

505 difficult to align perfectly with our findings. Recently, Reimúndez et al. (2018) demonstrated 
that $\operatorname{Trpm} 8$ is required for thermoregulation in male mice when housed in colder environments, which corroborates our findings [16]. Interestingly, Reimúndez et al. (2018) also demonstrated that this difficulty in maintaining core temperature was associated with greater tail vasodilation and heat loss in male mice with global deletion of $\operatorname{Trpm} 8$, indicating that this cold-sensing channel has an important role in regulating both thermogenesis and heat dissipation [16]. However, female core temperature status was not investigated in any of these studies. In contrast, one strength of our study is the comprehensive analyses of mice of both sexes. Cooling sensitivity is the first step to activate the cold response neuronal mechanism that modulates lipolysis and energy expenditure [39]. In our study, we observed that cold-induced weight loss occurred in both sexes, irrespective of the genotype. However, there were Trpm8and sex-differences among the various adipose tissues' response to housing temperature. Male mice housed at $4{ }^{\circ} \mathrm{C}$ exhibited BAT expansion with fewer lipid droplets and increased Ucpl expression in WT, which is indicative of thermogenesis activity. However, this difference did appear to be blunted in KO mice (Figure 5). Moraes et al. (2017) found reduced Ucpl and Pparg expression at ZT2 and ZT14 in male TRPM8-KO mice ranging from 3-6 months of age, compared to ours that were 12 months [20]. Although we did not see lower Ucpl or Pparg in our room temperature mice, we expect that this difference might be due to the age of the mice or the time of the day that our tissues were collected ZT6-ZT10. However, our overall finding that thermogenesis is impaired in males is consistent with Moraes et al. finding of reduced Ucpl [20]. Further, we found that cold housing in male KO, but not WT, mice induced BAT expression of other fatty acid metabolism markers (Acadl, Prdm16, and $P g c 1 \alpha$ ) as well as a robust expression of other thermogenic markers such as Cidea and Dio2 in BAT, which may have been compensatory for a lack of $U c p l$ induction compared to room temperature. 
In females, we found that Trpm8 deletion led to an increase in Ucpl expression and

530

531

532

533

534

535

536

537

538

539

540

541

542

543

544

545

546

547

548

549

550

reduction in lipid droplets in BAT during cold exposure, indicating TRPM8 was not required for the response. Furthermore, cold reduced gWAT mass in female mice from both genotypes, in addition to increasing expression of fatty acid metabolism (Acadl, Pgcl $\alpha, P d k 4$ ) and thermogenic (Ucp1, Cidea, Dio2) markers. It should be considered that estrogen status may play a role in sex-differences in thermogenesis and WAT beiging found in the present study. Several studies observed that the beiging process does take place in gWAT in females [40,41]. Increased expression of beiging markers such as Ucpl, Pgcla, Elovl3, Cidea was observed in gWAT after either 10 days of cold exposure [41] or $\beta 3$-adrenergic receptor agonist treatment [40] in female mice. Kim et al. (2016) demonstrated that gWAT in females is more susceptible to the beiging process than in males, due to more extensive sympathetic innervation inducing brown adipogenesis [40]. Also, the authors showed that sympathetic innervation of gWAT is sexhormone dependent, as reduced tyrosine hydroxylase protein levels and lack of beiging of gWAT was found after chemical ovarian ablation [40]. Indeed, lipolysis can be directly modulated by estrogen through estrogen receptor alpha $(\operatorname{ER} \alpha)$ signaling in BAT and WAT adipocytes [42]. Estrogen also has been described to play a critical role in cold sensitivity and hyperalgesia $[43,44]$, which are also functions thought to be regulated by Trpm8 $[45,46]$. However, interestingly, a previous preclinical study observed that Trpm 8 expression was upregulated in the skin of ovariectomized rats compared to sham control rats [47] and $\beta$-estradiol treatment might reduce Trpm8 overexpression in the skin of ovariectomized rats [48]. These findings support our data that suggest regulation of energy metabolism in female mice is independent of Trpm 8 coldsensing function and estrogen might be a more relevant factor to normal thermoregulation in 
551 females. It is unclear however, whether ovariectomized mice, or mice aged to natural

552 amenorrhea, would have a response to cold that is modified by Trpm 8 deletion.

568 found to be regulated by TRPV1 [50], which once more indicates TRPM8 is a major regulator of non-shivering thermogenesis.

571 maintenance in male mice and its absence triggers a compensatory response to counteract

572 reduction in core temperature. Moreover, $\operatorname{Trpm} 8$ does not appear to regulate the bone response to

573 colder environments, where it is presumed that the sympathetic nervous system-mediated stress 
574 response and/or diversion of energy away from bone contributes to bone loss. Interestingly,

575 deletion of Trpm8 was associated with bone size and shape differences in male mice as well.

576 Therefore, although any bone loss associated with acute cold housing may be independent of

577 TRPM8, low bone mass found in Trpm8-KO mice compared to WT, more striking in males,

578 indicates that the functions of TRPM8 could contribute to bone modeling and remodeling

579 throughout lifespan.

$581 \quad$ Limitations

582 Some limitations of this study do exist. First, addition of a thermoneutral group would potentially

583 exacerbate differences observed, and could provide additional insight into whether Trpm8

584 regulates bone and marrow adiposity independent of cold temperature sensation and subsequent

585 physiologic response. We regret that we did not have the capability to age mice to 52 weeks of

586 age in a thermoneutral $\left(\sim 28-30^{\circ} \mathrm{C}\right)$ rodent incubator when this study was first designed. Next,

587 because the room temperature mice were housed in a separate room from the cold-treated, we

588 cannot exclude the possibility that the additional noise of the cold room contributed to the

589 phenotype. There is no known association between noise stress and changes in brown adipose

590 tissue, but there are some studies examining the impact of chronic mild stress (CMS), of which

591 one of the stressors is noise, on bone density. One study found that the CMS caused bone loss,

592 and this could be blocked by propranolol, which suggests the SNS is involved [54]. However,

593 other stressors were involved in that study, including water deprivation, continuous overnight

594 illumination, stroboscopic illumination, cage tilt, and time in a soiled cage. Thus, it is unclear

595 whether noise alone would have influenced bone microarchitecture. Although the sound was

596 greater in the cold room in our study, it was consistent over time, and the fact remains that 
597

598

599

600

601

602

603

604

605

606

607

608

609

610

611

612

613

614

615

616

617

618

619

620

compared to WT males, and females of both genotypes all treated in the cold, the body

temperature in the male $\mathrm{KO}$ mice had a delayed response to cold. Other key findings, like

Trpm8-KO mediated bone loss, were not dependent upon housing conditions. Light intensity was not measured, but was similar and from the ceiling in both rooms. Furthermore, additional $\mathrm{N}$ would have helped to reduce biological variability, which was high in some of the secondary outcomes of interest, such as inguinal WAT mass and expression of Ucpl in both BAT and gWAT. Although differences were not detected in iWAT mass, it is possible that histology and mRNA analyses of this tissue would have provided additional valuable information. However, iWAT samples were not saved to analyze at a later time point. Additionally, examining the thermogenic response at the time point where we observed major differences in body temperature in male mice exposed to cold would have provided better insight into mechanism. However, analysis of bone defects after cold were the primary outcomes of interest, and these would not have been apparent at such an early time point.

Despite these limitations, the current data provide new insight into our understanding of the role of $\operatorname{Trpm} 8$ in the regulation of thermogenesis and skeletal homeostasis and demonstrate important and unexpected sex-differences in these processes. This work suggests that in males in particular, TRPM8 is necessary for normal thermoregulation and bone density, while in females, TRPM8 regulates marrow adiposity.

\section{Acknowledgments}

The authors thank Phuong Le and Casey Doucette for the assistance during the cold housing experiment, and Audrey Bergeron for critical review of the manuscript. This work was supported by the National Institute of Arthritis And Musculoskeletal And Skin Diseases (NIAMS) and the 
621 National Institute of General Medical Sciences (NIGMS) of the National Institutes of Health

622 (NIH) under award numbers K01AR067858 and P20GM121301 to KJM. This work utilized

623 services of the Maine Medical Center Research Institute (MMCRI) Molecular Phenotyping Core,

624 which is supported by NIH/NIGMS P30GM106391, the Physiology Core, which is supported by

625 NIH/NIGMS P30GM106391 and P20GM121301, the Histopathology and Histomorphometry

626 Core, which is supported by NIH/NIGMS P30GM106391, P20GM121301, and P30103392, and

627 the Mouse Transgenic and In Vivo Imaging Core which is supported by NIH/NIGMS

628 P30GM103392. All cores also received

629 support from the Norther New England Clinical and Translational Research Network

630 NIH/NIGMS U54GM115516. The content is solely the responsibility of the authors and does not 631 necessarily represent the official views of the National Institutes of Health.

633 Authors Contributions

634 ALC was responsible for data acquisition, data analysis, interpretation, drafting and critical 635 review of the manuscript. AT was responsible for data acquisition, data analysis, interpretation, 636 drafting and critical review of the manuscript. DJB was responsible for data acquisition, data 637 analysis, interpretation, drafting and critical review of the manuscript. SC was responsible for 638 data acquisition, data analysis, interpretation, drafting and critical review of the manuscript. RN 639 was responsible for data acquisition, data analysis and critical review of the manuscript. MRR 640 was responsible for data interpretation and critical review of the manuscript. MLB was

641 responsible for data interpretation and critical review of the manuscript. KJM was responsible for 642 experimental design, data acquisition, data analysis, interpretation, drafting, and critical review 643 of the manuscript. All authors had final approval of the manuscript. 


\section{Declaration of interests}

646 The authors have declared that no conflict of interest exists.

647

648

\section{References}

649 1. Iwaniec UT, Philbrick KA, Wong CP, Gordon JL, Kahler-Quesada AM, Olson DA, et al. 650 Room temperature housing results in premature cancellous bone loss in growing female mice: implications for the mouse as a preclinical model for age-related bone loss.

652 Osteoporos Int. 2016;27: 3091-3101. doi:10.1007/s00198-016-3634-3

2. Fedorenko A, Lishko P V., Kirichok Y. Mechanism of fatty-acid-dependent UCP1 uncoupling in brown fat mitochondria. Cell. 2012;151: 400-413. doi:10.1016/j.cell.2012.09.010

656 3. Tan CL, Knight ZA. Regulation of Body Temperature by the Nervous System. Neuron. 657 2018;98: 31-48. doi:10.1016/j.neuron.2018.02.022

658 4. Contreras GA, Lee YH, Mottillo EP, Granneman JG. Inducible brown adipocytes in

659 subcutaneous inguinal white fat: The role of continuous sympathetic stimulation. Am J

5. Bahler L, Verberne HJ, Admiraal WM, Stok WJ, Soeters MR, Hoekstra JB, et al. young and old, and the lean and obese. J Nucl Med. 2016;57: 372-377. doi:10.2967/jnumed.115.165829 
668 7. Zoico E, Rubele S, De Caro A, Nori N, Mazzali G, Fantin F, et al. Brown and beige adipose tissue and aging. Front Endocrinol (Lausanne). 2019;10: 1-10.

670 doi:10.3389/fendo.2019.00368

671 8. Wang W, Ishibashi J, Trefely S, Shao M, Cowan AJ, Sakers A, et al. A PRDM16-Driven Metabolic Signal from Adipocytes Regulates Precursor Cell Fate. Cell Metab. 2019;30:

673 174-189.e5. doi:10.1016/j.cmet.2019.05.005

6749 Johnell O, Kanis JA. An estimate of the worldwide prevalence and disability associated 675 with osteoporotic fractures. Osteoporos Int. 2006;17: 1726-1733. doi:10.1007/s00198$676 \quad 006-0172-4$

677 10. Odén A, McCloskey E V., Kanis JA, Harvey NC, Johansson H. Burden of high fracture 678 probability worldwide: secular increases 2010-2040. Osteoporos Int. 2015;26: 22432248. doi:10.1007/s00198-015-3154-6

11. Elefteriou F. Neuronal signaling and the regulation of bone remodeling. Cell Mol Life Sci. 2005;62: 2339-2349. doi:10.1007/s00018-005-5175-3

682 12. Motyl KJ, Bishop KA, Demambro VE, Bornstein SA, Le P, Kawai M, et al. Altered thermogenesis and impaired bone remodeling in Misty mice. J Bone Miner Res. 2013;28: 1885-1897. doi:10.1002/jbmr.1943

685 13. Scheller EL, Doucette CR, Learman BS, Cawthorn WP, Khandaker S, Schell B, et al. constitutive marrow adipose tissues. Nat Commun. 2015;6: 7808. doi:10.1038/ncomms8808

14. Dhaka A, Murray AN, Mathur J, Earley TJ, Petrus MJ, Patapoutian A. TRPM8 Is 
Required for Cold Sensation in Mice. Neuron. 2007;54: 371-378. doi:10.1016/j.neuron.2007.02.024

15. McKemy DD, Neuhausser WM, Julius D. Identification of a cold receptor reveals a general role for TRP channels in thermosensation. Nature. 2002;416: 52-58. doi:10.1038/nature719

16. Reimúndez A, Fernández-Peña C, García G, Fernández R, Ordás P, Gallego R, et al. Deletion of the cold thermoreceptor TRPM8 increases heat loss and food intake leading to reduced body temperature and obesity in mice. J Neurosci. 2018;38: 3643-3656. doi:10.1523/JNEUROSCI.3002-17.2018

17. Zhu Z, Ma S, Yu H, Zhao Z, Luo Z, Chen J, et al. Activation of the cold-sensing TRPM8 channel triggers UCP1-dependent thermogenesis and prevents obesity. J Mol Cell Biol. 2012;4: 88-96. doi:10.1093/jmcb/mjs001

18. McCoy DD, Zhou L, Nguyen AK, Watts AG, Donovan CM, McKemy DD. Enhanced insulin clearance in mice lacking TRPM8 channels. Am J Physiol - Endocrinol Metab. 2013;305: 78-88. doi:10.1152/ajpendo.00542.2012

19. Rossato M, Granzotto M, Macchi V, Porzionato A, Petrelli L, Calcagno A, et al. Human white adipocytes express the cold receptor TRPM8 which activation induces UCP1 expression, mitochondrial activation and heat production. Mol Cell Endocrinol. 2014;383: 137-146. doi:10.1016/j.mce.2013.12.005

20. Moraes MN, de Assis LVM, Henriques F dos S, Batista ML, Güler AD, Castrucci AM de L. Cold-sensing TRPM8 channel participates in circadian control of the brown adipose tissue. Biochim Biophys Acta - Mol Cell Res. 2017;1864: 2415-2427. doi:10.1016/j.bbamcr.2017.09.011 
713 21. Jiang C, Zhai M, Yan D, Li D, Li C, Zhang Y, et al. Dietary menthol-induced TRPM8

714

715

716

717

718

719

720

721

722

723

724

725

726

727

728

729

730

731

732

733

734

735

activation enhances WAT 1C "browning 1D” and ameliorates diet-induced obesity.

Oncotarget. 2017;8: 75114-75126. doi:10.18632/oncotarget.20540

22. Ma S, Yu H, Zhao Z, Luo Z, Chen J, Ni Y, et al. Activation of the cold-sensing TRPM8 channel triggers UCP1-dependent thermogenesis and prevents obesity. J Mol Cell Biol. 2012;4: 88-96. doi:10.1093/jmcb/mjs001

23. Motyl KJ, DeMambro VE, Barlow D, Olshan D, Nagano K, Baron R, et al. Propranolol attenuates risperidone-induced trabecular bone loss in female mice. Endocrinology.

2015;156: 2374-2383. doi:10.1210/en.2015-1099

24. Fischer AW, Cannon B, Nedergaard J. Optimal housing temperatures for mice to mimic the thermal environment of humans: An experimental study. Mol Metab. 2018.

doi:10.1016/j.molmet.2017.10.009

25. Eliceiri K, Schneider CA, Rasband WS, Eliceiri KW. NIH Image to ImageJ $\square: 25$ years of image analysis HISTORICAL commentary NIH Image to ImageJ $\square: 25$ years of image analysis. Nat Methods. 2012;9: 671-675. doi:10.1038/nmeth.2089

26. T. Ferreira WR. ImageJ User Guide IJ 1.46r. IJ 146r. 2012; 185. doi:10.1038/nmeth.2019

27. Bouxsein ML, Boyd SK, Christiansen BA, Guldberg RE, Jepsen KJ, Müller R. Guidelines for assessment of bone microstructure in rodents using micro-computed tomography. J Bone Miner Res. 2010;25: 1468-1486. doi:10.1002/jbmr.141

28. Vengellur A, LaPres JJ. The role of hypoxia inducible factor $1 \alpha$ in cobalt chloride induced cell death in mouse embryonic fibroblasts. Toxicol Sci. 2004. doi:10.1093/toxsci/kfh278

29. Seale et al. PRDM16 Controls a Brown Fat/Skeletal Muscle Switch. Bone. 2008;23: 1-7. doi:10.1038/nature07182 
30. Sanchez-Gurmaches $\square$; Guertin D. Adipocytes arise from multiple lineages that are

737

738

739

740

741

742

743

744

745

746

747

748

749

750

751

752

753

754

755

756

757

758

heterogeneously and dynamically distributed Access. Nat Commun. 2014;5: 4099.

doi:10.1038/ncomms5099

31. Cooper MP, Uldry M, Kajimura S, Arany Z, Spiegelman BM. Modulation of PGC-1 coactivator pathways in brown fat differentiation through LRP130. J Biol Chem. 2008. doi:10.1074/jbc.M805431200

32. Scheller EL, Doucette CR, Learman BS, Cawthorn WP, Khandaker S, Schell B, et al. Region-specific variation in the properties of skeletal adipocytes reveals regulated and constitutive marrow adipose tissues. Nat Commun. 2015;6: 1-13.

doi: $10.1038 /$ ncomms 8808

33. Takashima Y, Ma L, McKemy DD. The development of peripheral cold neural circuits based on TRPM8 expression. Neuroscience. 2010;169: 828-842.

doi:10.1016/j.neuroscience.2010.05.039

34. Abed E, Labelle D, Martineau C, Loghin A, Moreau R. Expression of transient receptor potential (TRP) channels in human and murine osteoblast-like cells. Mol Membr Biol. 2009;26: 146-158. doi:10.1080/09687680802612721

35. Takahashi N, Matsuda Y, Sato K, De Jong PR, Bertin S, Tabeta K, et al. Neuronal TRPV1 activation regulates alveolar bone resorption by suppressing osteoclastogenesis via CGRP.

Sci Rep. 2016;6: 1-11. doi:10.1038/srep29294

36. Nilius B, Voets T, Peters J. TRP channels in disease. Sci STKE. 2005;2005: 1-10.

37. Wee NKY, Lorenz MR, Bekirov Y, Jacquin MF, Scheller EL. Shared autonomic pathways connect bone marrow and peripheral adipose tissues across the central neuraxis. Front Endocrinol (Lausanne). 2019;10: 1-16. doi:10.3389/fendo.2019.00668 
38. Bautista DM, Siemens J, Glazer JM, Tsuruda PR, Basbaum AI, Stucky CL, et al. The menthol receptor TRPM8 is the principal detector of environmental cold. Nature. 2007;448: 204-208. doi:10.1038/nature05910

39. Shin H, Ma Y, Chanturiya T, Cao Q, Wang Y, Kadegowda AKG, et al. Lipolysis in Brown Adipocytes Is Not Essential for Cold-Induced Thermogenesis in Mice. Cell Metab. 2017;26: 764-777.e5. doi:10.1016/j.cmet.2017.09.002

40. Kim SN, Jung YS, Kwon HJ, Seong JK, Granneman JG, Lee YH. Sex differences in sympathetic innervation and browning of white adipose tissue of mice. Biol Sex Differ. 2016;7: 1-13. doi:10.1186/s13293-016-0121-7

41. Rosell M, Kaforou M, Frontini A, Okolo A, Chan YW, Nikolopoulou E, et al. Brown and white adipose tissues: Intrinsic differences in gene expression and response to cold exposure in mice. Am J Physiol - Endocrinol Metab. 2014;306.

doi:10.1152/ajpendo.00473.2013

42. Clookey SL, Welly RJ, Shay D, Woodford ML, Fritsche KL, Rector RS, et al. Beta 3 adrenergic receptor activation rescues metabolic dysfunction in female estrogen receptor alpha-null mice. Front Physiol. 2019;10: 1-15. doi:10.3389/fphys.2019.00009

43. Cankar K, Music M, Finderle Z. Cutaneous microvascular response during local cold exposure - the effect of female sex hormones and cold perception. Microvasc Res. 2016;108: 34-40. doi:10.1016/j.mvr.2016.07.006

44. Smeester BA, O’Brien EE, Michlitsch KS, Lee JH, Beitz AJ. The relationship of bonetumor-induced spinal cord astrocyte activation and aromatase expression to mechanical hyperalgesia and cold hypersensitivity in intact female and ovariectomized mice. Neuroscience. 2016;324: 344-354. doi:10.1016/j.neuroscience.2016.03.030 
782

783

784

785

786

787

788

789

790

791

792

793

794

795

796

797

798

799

800

801

802

803

804

45. Weyer AD, Lehto SG. Development of TRPM8 antagonists to treat chronic pain and migraine. Pharmaceuticals. 2017;10: 1-9. doi:10.3390/ph10020037

46. Caudle RM, Caudle SL, Jenkins AC, Ahn AH, Neubert JK. Sex differences in mouse Transient Receptor Potential Cation Channel, Subfamily M, Member 8 expressing trigeminal ganglion neurons. PLoS One. 2017;12: 1-20. doi:10.1371/journal.pone.0176753

47. Noguchi W, Ishizuka O, Imamura T, Kurizaki Y, Yamagishi T, Yokoyama H, et al. The relationship between $\alpha 1$-adrenergic receptors and TRPM8 channels in detrusor overactivity induced by cold stress in ovariectomized rats. J Urol. 2013;189: 1975-1981. doi:10.1016/j.juro.2012.10.014

48. Kubo T, Tsuji S, Amano T, Yoshino F, Niwa Y, Kasahara K, et al. Effects of $\beta$-estradiol on cold-sensitive receptor channel TRPM8 in ovariectomized rats. Exp Anim. 2017;66: 337-343. doi:10.1538/expanim.17-0028

49. Winter Z, Gruschwitz P, Eger S, Touska F, Zimmermann K. Cold temperature encoding by cutaneous TRPA1 and TRPM8-carrying fibers in the mouse. Front Mol Neurosci. 2017;10. doi:10.3389/fnmol.2017.00209

50. Feketa V V., Balasubramanian A, Flores CM, Player MR, Marrelli SP. Shivering and tachycardic responses to external cooling in mice are substantially suppressed by TRPV1 activation but not by TRPM8 inhibition. Am J Physiol - Regul Integr Comp Physiol. 2013;305: 1040-1050. doi:10.1152/ajpregu.00296.2013

51. Ukropec J, Anunciado RP, Ravussin Y, Hulver MW, Kozak LP. UCP1-independent thermogenesis in white adipose tissue of cold-acclimated Ucp1-/- mice. J Biol Chem. 2006;281: 31894-31908. doi:10.1074/jbc.M606114200 
805 52. Gao Y, Qimuge NR, Qin J, Cai R, Li X, Chu GY, et al. Acute and chronic cold exposure 806 differentially affects the browning of porcine white adipose tissue. Animal. 2018;12: 1435-1441. doi:10.1017/S1751731117002981

808

53. Liang X, Pan J, Cao C, Zhang L, Zhao Y, Fan Y, et al. Transcriptional response of subcutaneous white adipose tissue to acute cold exposure in mice. Int J Mol Sci. 2019;20. doi:10.3390/ijms20163968

811 54. Yirmiya R, Goshen I, Bajayo A, Kreisel T, Feldman S, Tam J, et al. Depression induces bone loss through stimulation of the sympathetic nervous system. Proc Natl Acad Sci U S 


\section{Supplemental References}

818 Cooper, M.P., Uldry, M., Kajimura, S., Arany, Z., Spiegelman, B.M., 2008. Modulation of PGC-

8191 coactivator pathways in brown fat differentiation through LRP130. J. Biol. Chem. 283,

820 31960-31967. https://doi.org/10.1074/jbc.M805431200

821 Sanchez-Gurmaches $\square$; Guertin, D., 2014. Adipocytes arise from multiple lineages that are

822 heterogeneously and dynamically distributed Access. Nat Commun. 5, 4099.

823

https://doi.org/10.1038/ncomms5099

824 Seale et al., 2008. PRDM16 Controls a Brown Fat/Skeletal Muscle Switch. Bone 23, 1-7.

825

https://doi.org/10.1038/nature07182

826

827 
bioRxiv preprint doi: https://doi.org/10.1101/2020.03.18.996694; this version posted October 30,2020. The copyright holder for this preprint (which was not certified by peer review) is the author/funder, who has granted bioRxiv a license to display the preprint in perpetuity. It is made available under aCC-BY-NC-ND 4.0 International license.

Figure 1

A

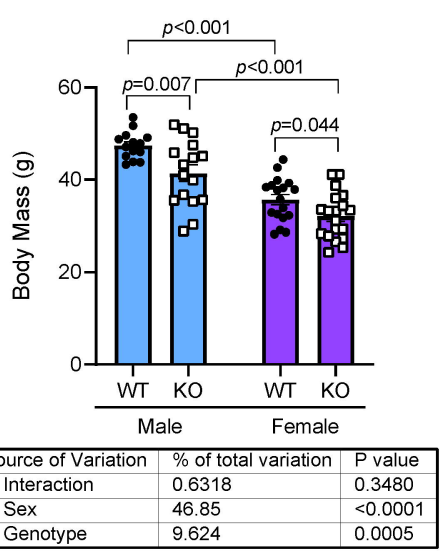

D

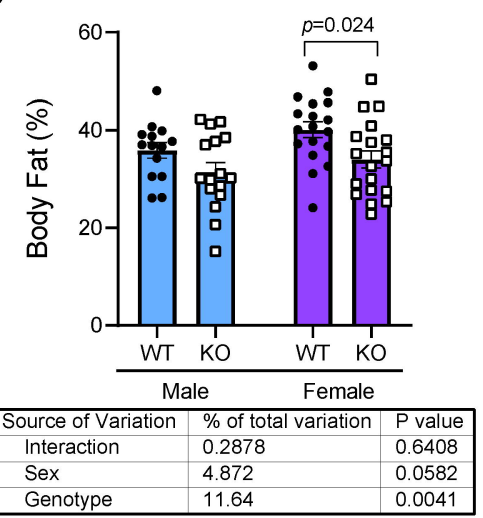

B

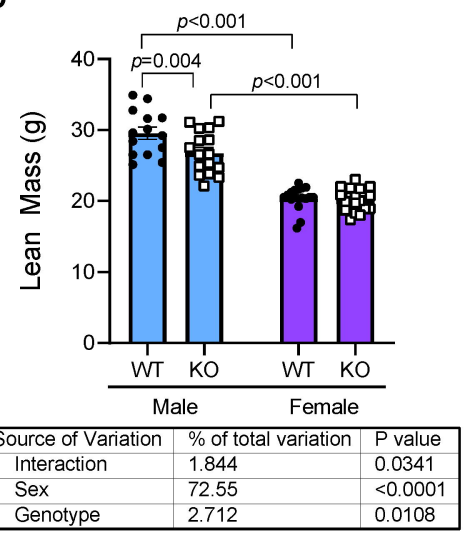

E

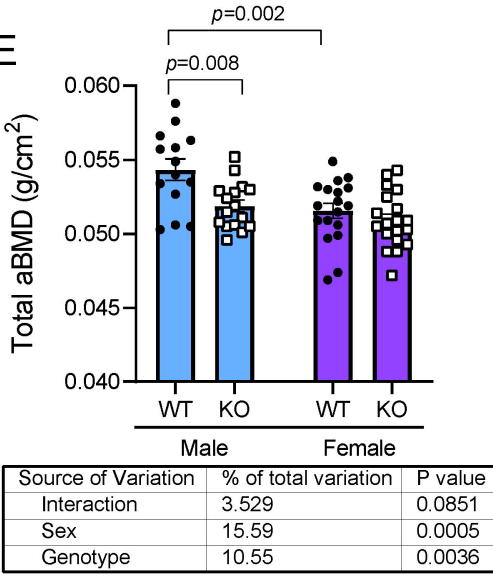

C

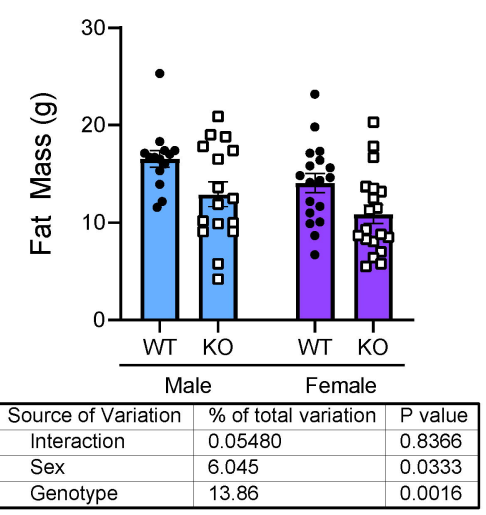

$\mathrm{F}$

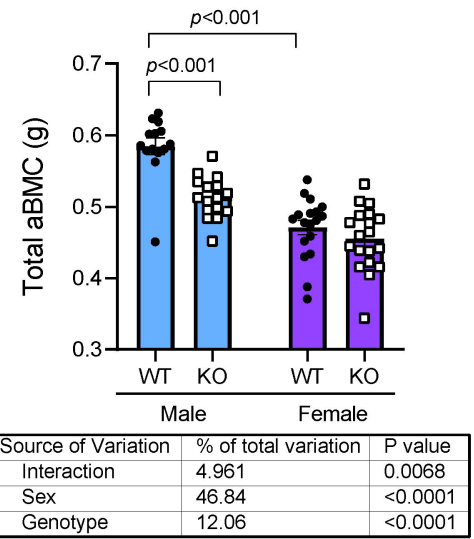


bioRxiv preprint doi: https://doi.org/10.1101/2020.03.18.996694; this version posted October 30, 2020. The copyright holder for this preprint (which was not certified by peer review) is the author/funder, who has granted bioRxiv a license to display the preprint in perpetuity. It is made available under aCC-BY-NC-ND 4.0 International license.

\section{Figure 2}

A

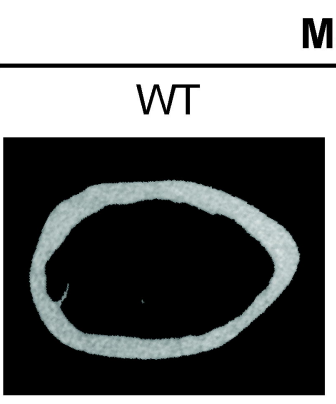

Male

C

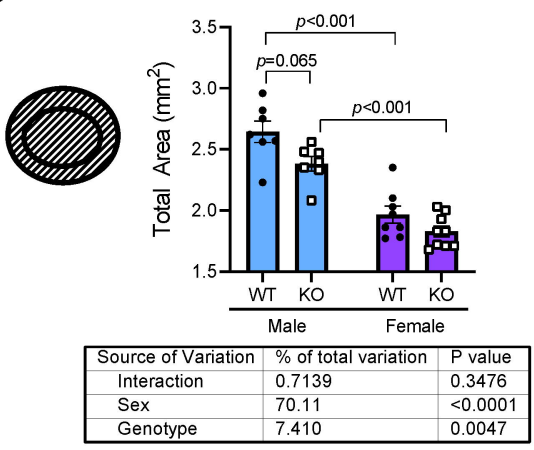

F

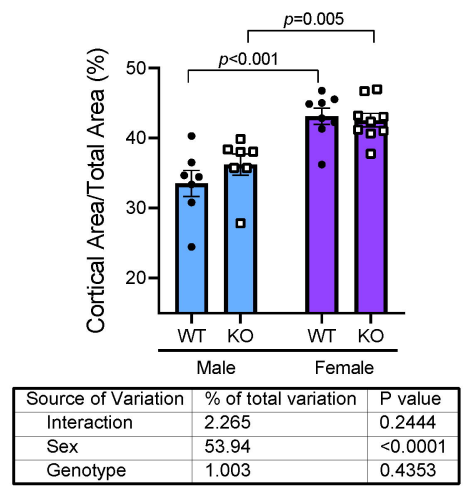

I

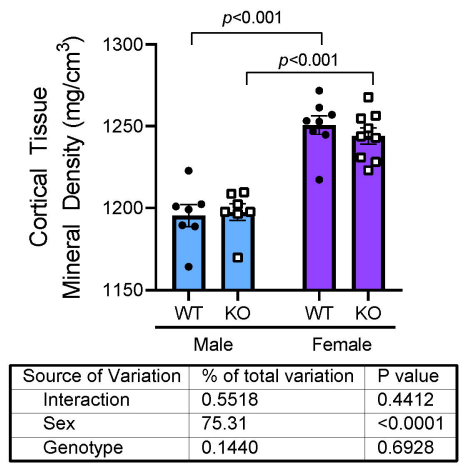

B

\section{Trpm8-KO}

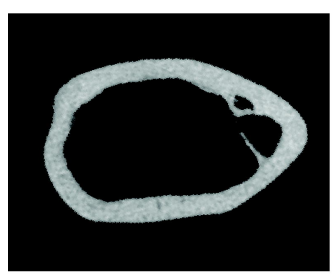

\section{Female}

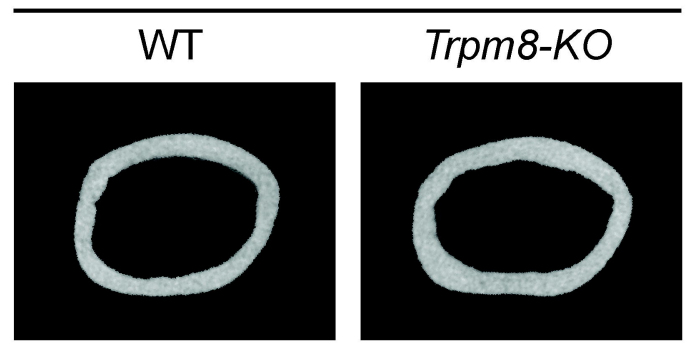

E

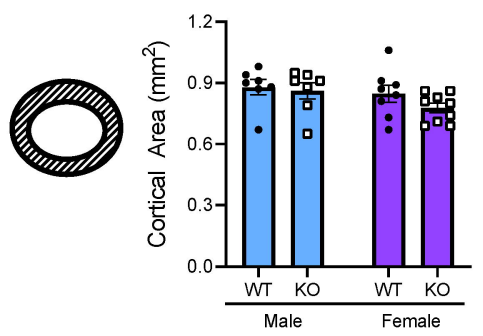

\begin{tabular}{|l|l|l|}
\hline Source of Variation & $\%$ of total variation & P value \\
\hline Interaction & 1.752 & 0.4599 \\
\hline Sex & 8.156 & 0.1174 \\
Genotype & 4.705 & 0.2298 \\
\hline
\end{tabular}

G

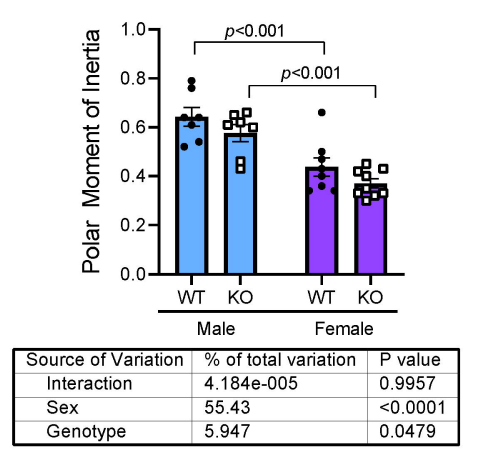

$\mathrm{H}$

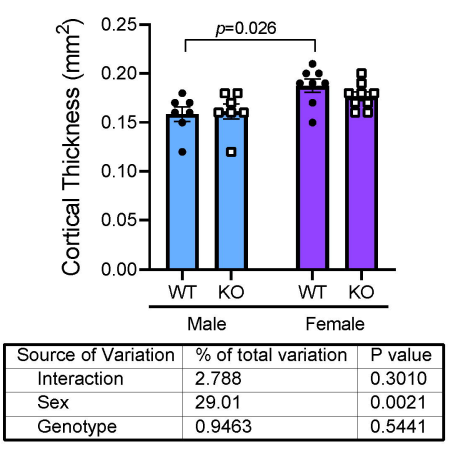

K

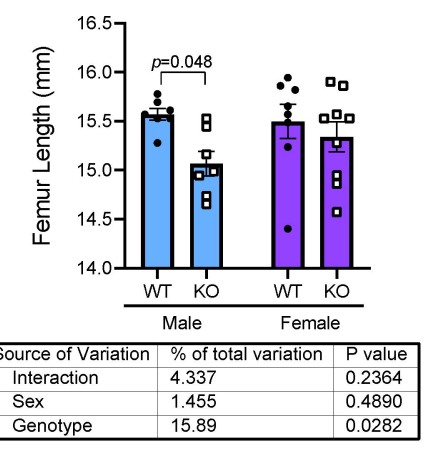


bioRxiv preprint doi: https://doi.org/10.1101/2020.03.18.996694; this version posted October 30, 2020. The copyright holder for this preprint (which was not certified by peer review) is the author/funder, who has granted bioRxiv a license to display the preprint in perpetuity. It is made available under aCC-BY-NC-ND 4.0 International license.

\section{Figure 3}

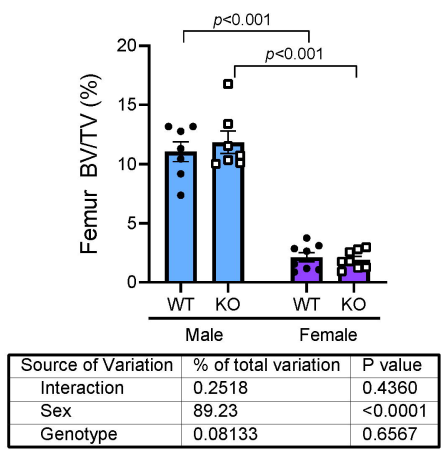




\section{Figure 4}

A

\section{Experimental Design}

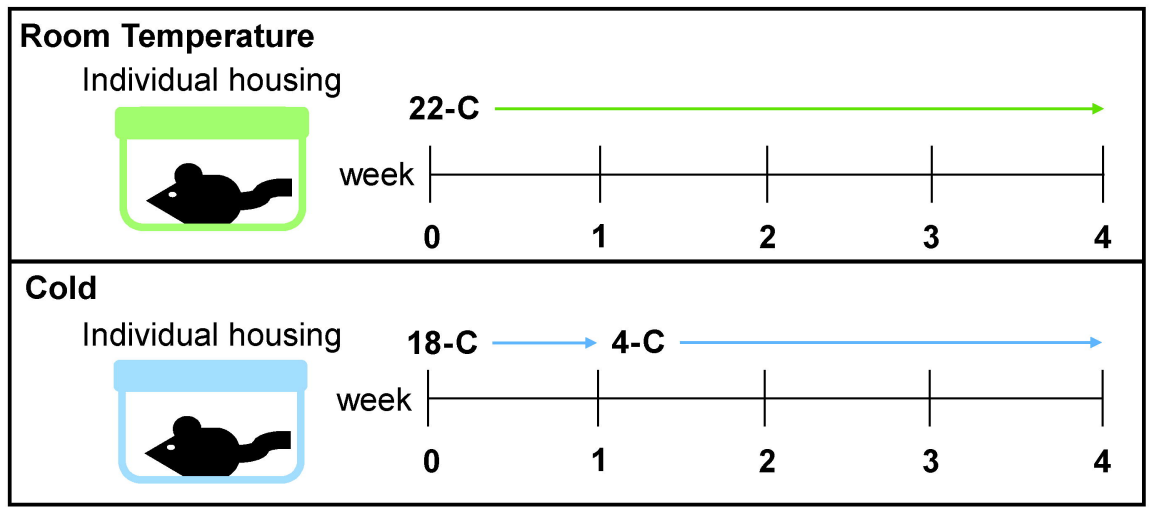

B

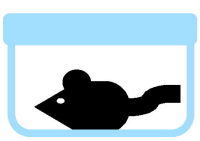

Male WT

- - Male Trpm8-KO

Female WT

- Female Trpm8-KO

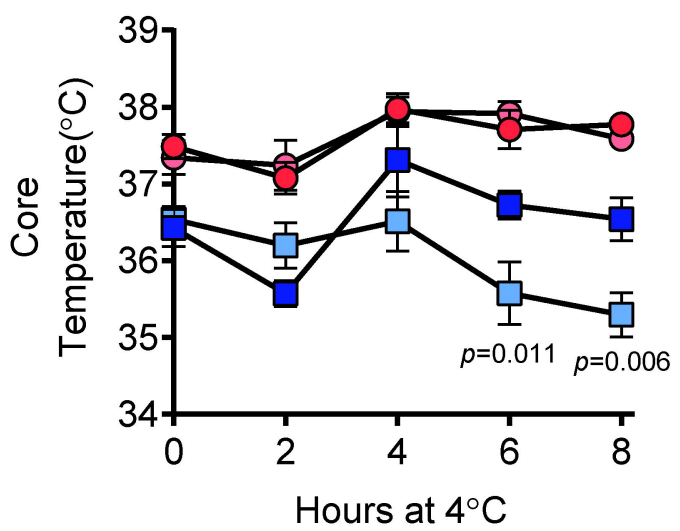

2-way ANOVA at $8 \mathrm{hrs:}$

\begin{tabular}{|l|l|l|}
\hline Source of Variation & \% of total variation & P value \\
\hline Interaction & 5.216 & 0.0187 \\
\hline Genotype & 9.561 & 0.0021 \\
\hline Sex & 58.15 & $<0.0001$ \\
\hline
\end{tabular}

C

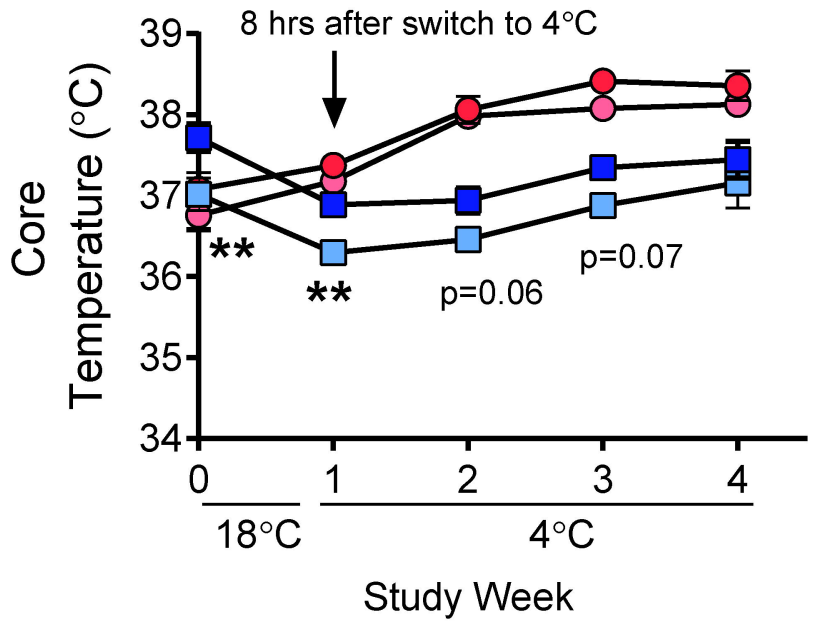

D

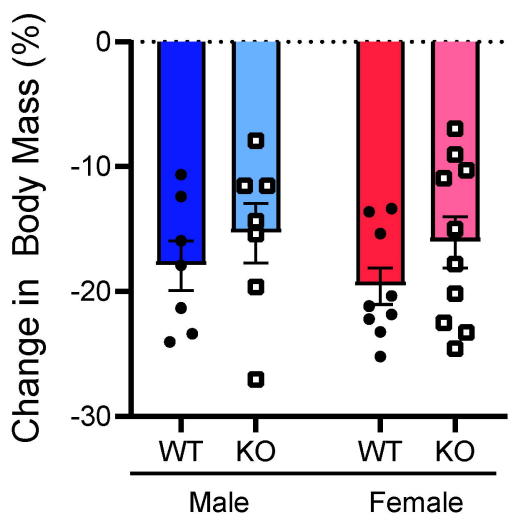

\begin{tabular}{|l|l|l|}
\hline Source of Variation & \% of total variation & P value \\
\hline Interaction & 0.1715 & 0.8168 \\
\hline Sex & 1.081 & 0.5618 \\
\hline Genotype & 7.356 & 0.1367 \\
\hline
\end{tabular}


A
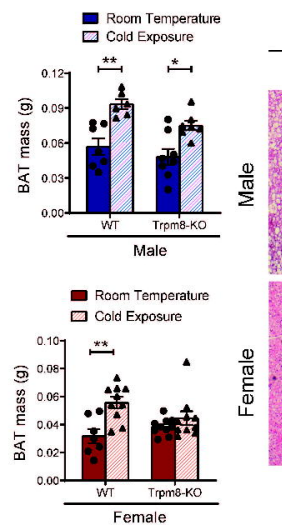

Figure 5

B

$\frac{\text { Trpm8-KO }}{\text { Room Temp. } \quad \text { Cold }}$
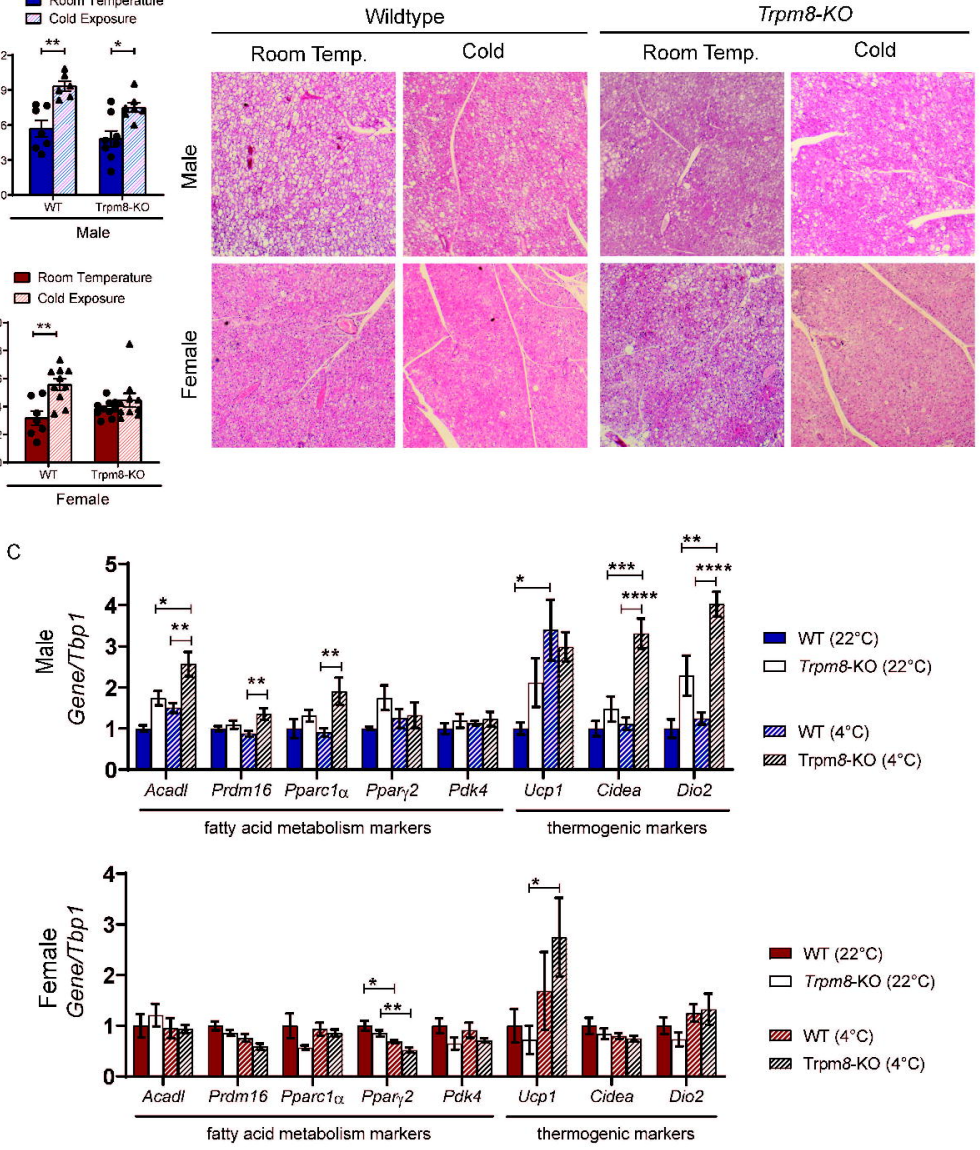

WT $\left(22^{\circ} \mathrm{C}\right)$

$\square$ Trom8-KO $\left(22^{\circ} \mathrm{C}\right)$

Iख⿴囗十 $W T\left(4^{\circ} \mathrm{C}\right)$

Trom8-KO $\left(4^{\circ} \mathrm{C}\right)$ 
Figure 6

A

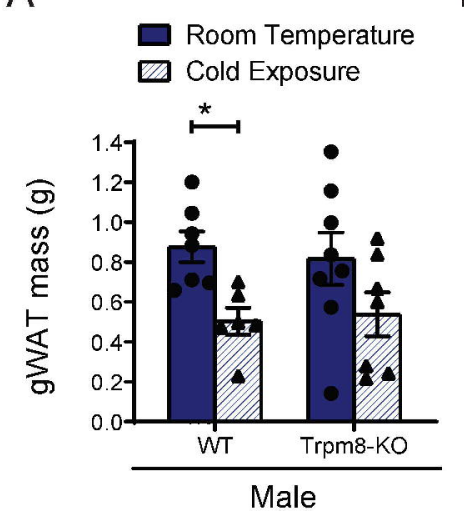

B

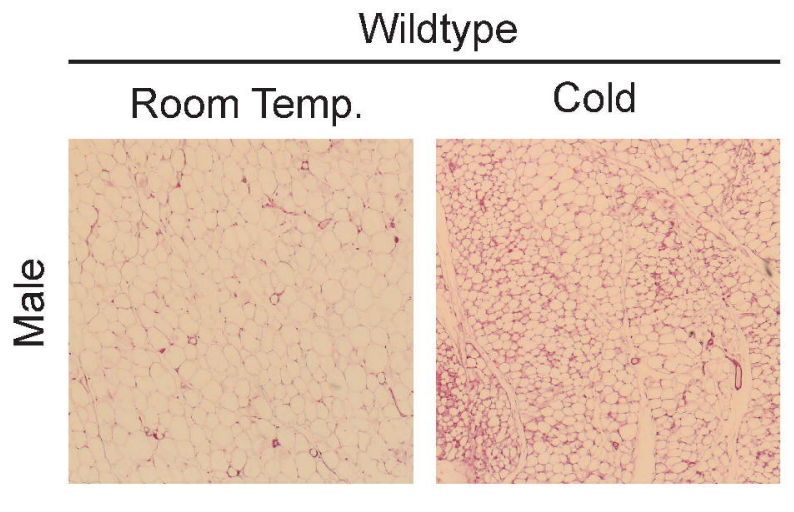

Trpm8-KO

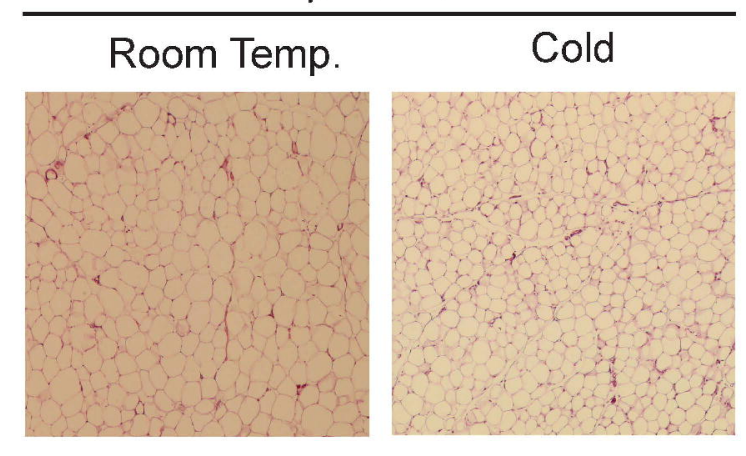

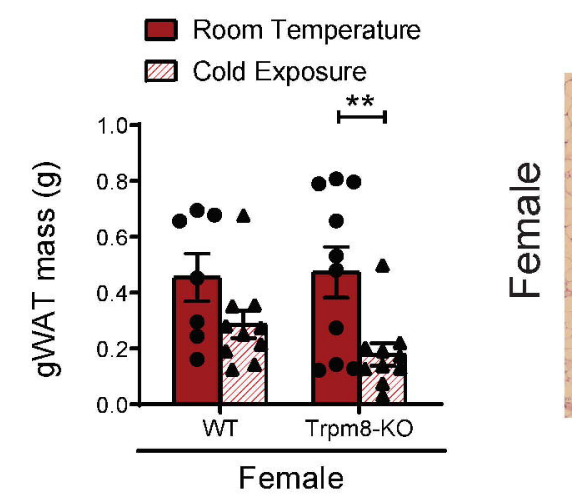

C
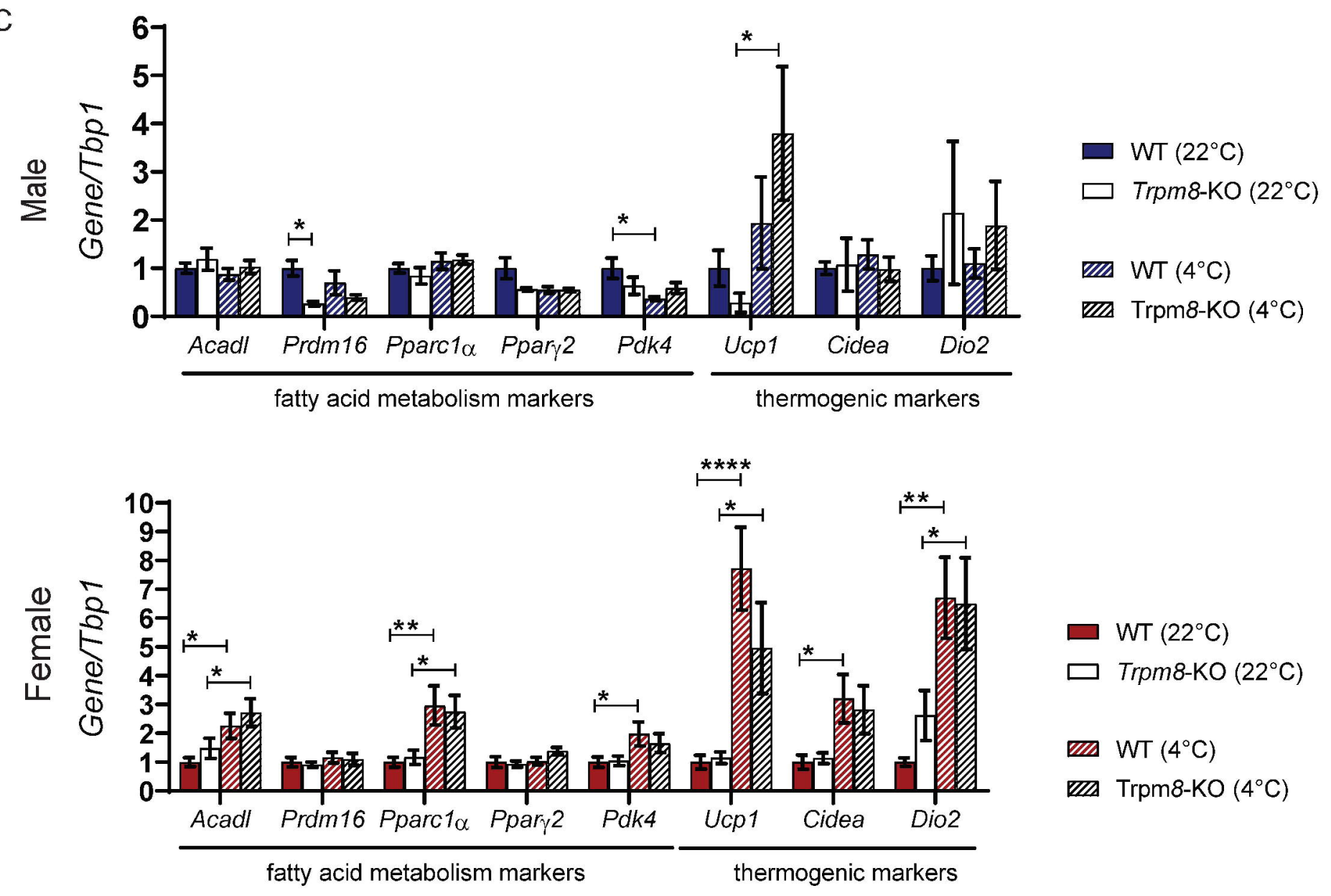
bioRxiv preprint doi: https://doi.org/10.1101/2020.03.18.996694; this version posted October 30, 2020. The copyright holder for this preprint (which was not certified by peer review) is the author/funder, who has granted bioRxiv a license to display the preprint in perpetuity. It is made available under aCC-BY-NC-ND 4.0 International license.

Figure 7

A

Male

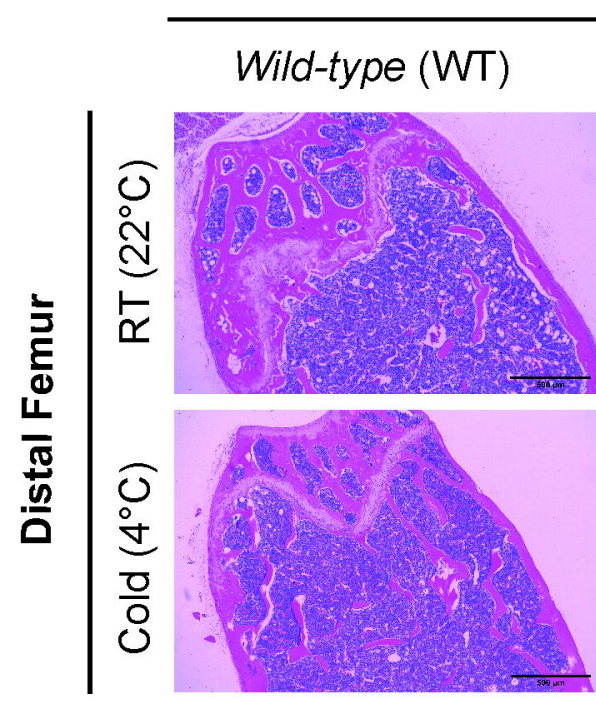

$\mathrm{B}$

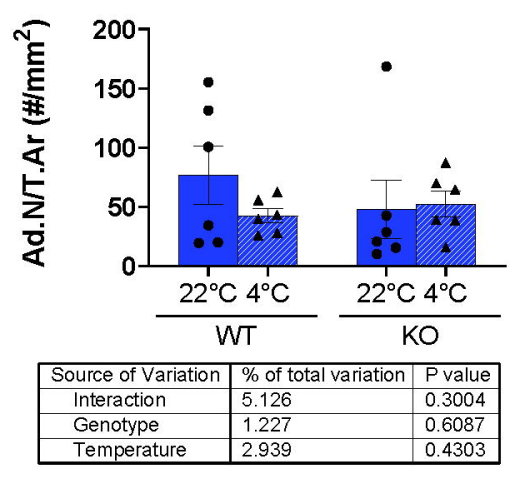

$\mathrm{E}$

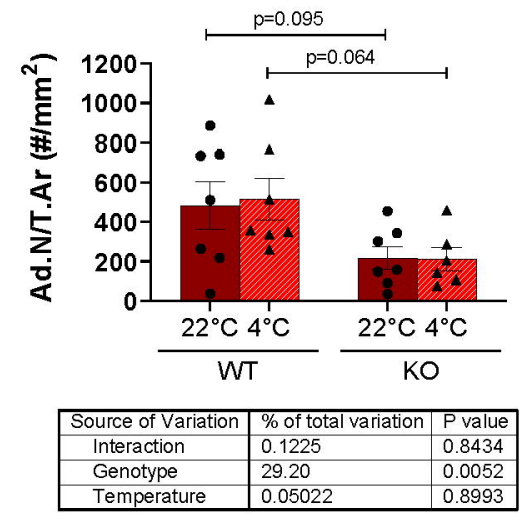

Female

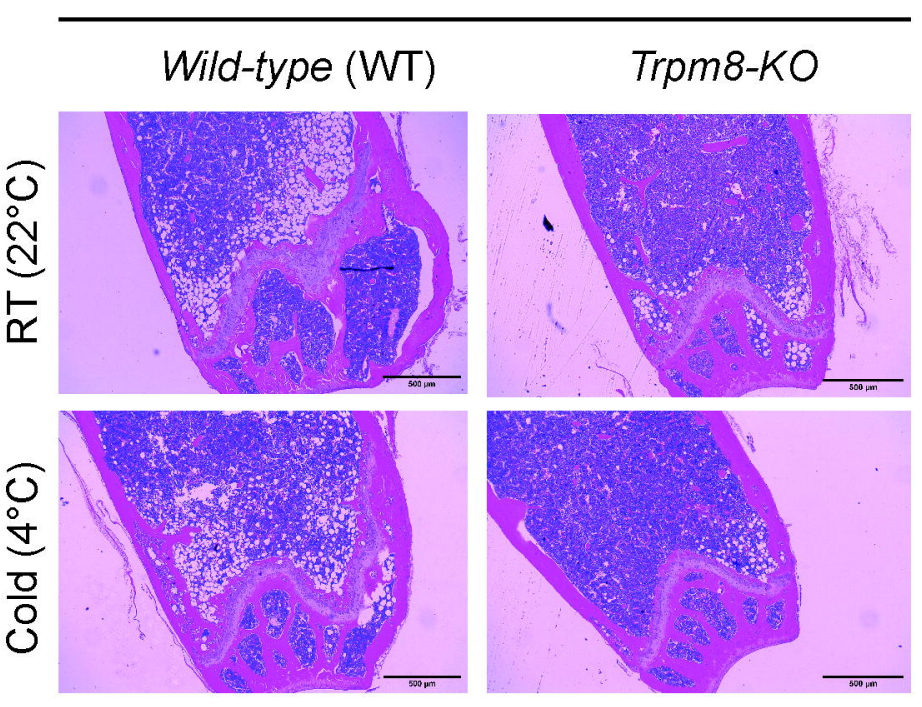

C

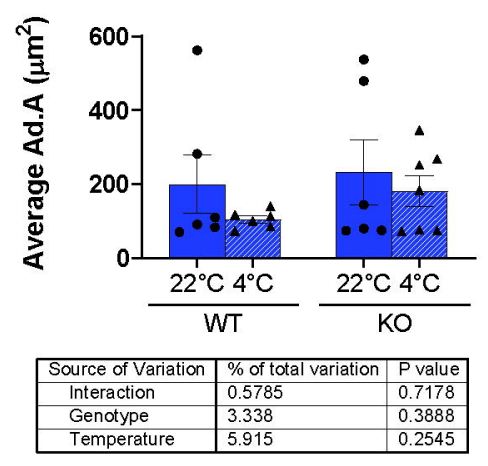

D

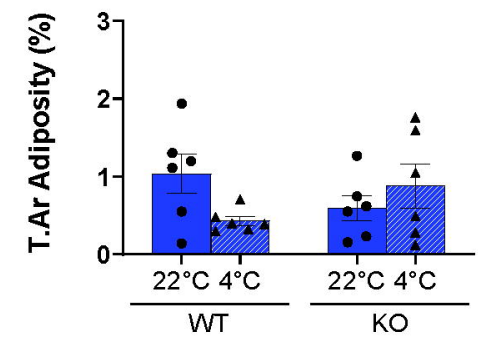

\begin{tabular}{|c|l|l|}
\hline Source of Variation & $\%$ of total variation & P value \\
\hline Interaction & 18.14 & 0.0452 \\
\hline Genotype & 0.0004265 & 0.9918 \\
\hline Temperature & 2.331 & 0.4529 \\
\hline
\end{tabular}

F

G

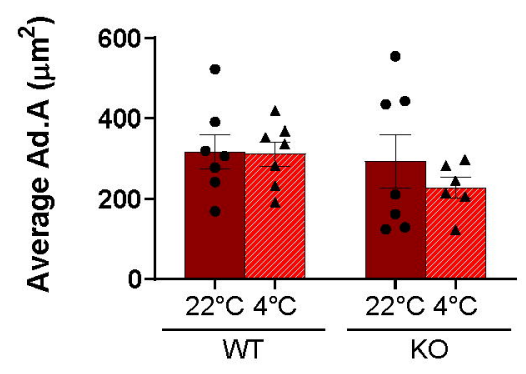

\begin{tabular}{|l|l|l|}
\hline Source of Variation & $\%$ of total variation & $\mathrm{P}$ value \\
\hline Interaction & 1.655 & 0.5242 \\
\hline Genotype & 5.539 & 0.2489 \\
\hline Temperature & 2.432 & 0.4411 \\
\hline
\end{tabular}
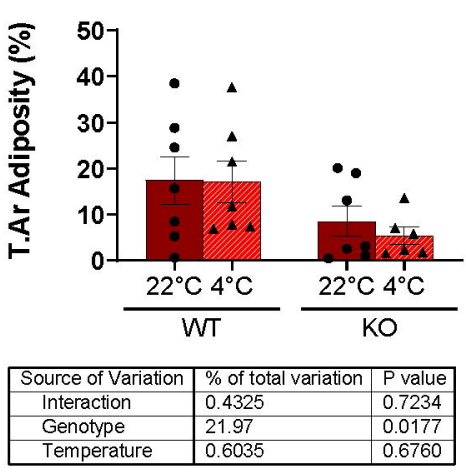